\title{
Detailed CFD Modelling of Open Refrigerated Display Cabinets
}

\author{
Pedro Dinis Gaspar, ${ }^{1}$ L. C. Carrilho Gonçalves, ${ }^{1}$ and R. A. Pitarma ${ }^{2}$ \\ ${ }^{1}$ Electromechanical Engineering Department, University of Beira Interior, Rua Fonte do Lameiro-Edifício 1 das Engenharias, \\ 6201-001 Covilhã, Portugal \\ ${ }^{2}$ Mechanical Engineering Department, Polytechnic Institute of Guarda, High School of Technology and Management, \\ Avenida Dr. Francisco Sá Carneiro No. 50, 6300-559 Guarda, Portugal
}

Correspondence should be addressed to Pedro Dinis Gaspar, dinis@ubi.pt

Received 8 January 2012; Accepted 3 February 2012

Academic Editor: Guan Heng Yeoh

Copyright (C) 2012 Pedro Dinis Gaspar et al. This is an open access article distributed under the Creative Commons Attribution License, which permits unrestricted use, distribution, and reproduction in any medium, provided the original work is properly cited.

\begin{abstract}
A comprehensive and detailed computational fluid dynamics (CFDs) modelling of air flow and heat transfer in an open refrigerated display cabinet (ORDC) is performed in this study. The physical-mathematical model considers the flow through the internal ducts, across fans and evaporator, and includes the thermal response of food products. The air humidity effect and thermal radiation heat transfer between surfaces are taken into account. Experimental tests were performed to characterize the phenomena near physical extremities and to validate the numerical predictions of air temperature, relative humidity, and velocity. Numerical and experimental results comparison reveals the predictive capabilities of the computational model for the optimized conception and development of this type of equipments. Numerical predictions are used to propose geometrical and functional parametric studies that improve thermal performance of the ORDC and consequently food safety.
\end{abstract}

\section{Introduction}

Nowadays, the energy spent during the commercialization of food products stored at refrigerated temperatures is about $50 \%$ of the total consumption of energy of a typical supermarket [1]. The growing of energy consumption in the commercial sector is due to the increasing demand of large quantities of perishable food products in urban areas and to an effective rigorous regulation of the sector as well as quality and food safety requirements of consumers. In past decades, the investments and costs associated with food refrigeration increased with the installation of refrigeration equipment to maintain perishable products in perfect conditions for consumption [2]. This trend continues as the worldwide demand for commercial refrigeration equipment that is projected to rise $5.2 \%$ annually through 2014 . Beverage equipment demand will post the fastest gains among products. Reach-in and walk-in coolers and freezers are expected to post solid gains due to their widespread use in all of the major markets. Display cabinets will benefit from a growing middle class, which will spur gains in the food and beverage retail segment [3]. A large part of the refrigeration equipments installed in supermarkets, and retail stores are vertical open refrigerated display cabinets (ORDCs). This merchandising solution contributes to the largest part of electrical energy consumption related with refrigeration on these sites [4]. This type of appliance is equipped with a recirculating air curtain that establishes an aerothermodynamics barrier between the conservation space and the environment, without physical restrictions for the consumer. Thus, the product to be acquired can be seen and handled without inconvenience.

The air curtain reduces the infiltration of exterior air at higher dry bulb temperature and specific humidity. The effectiveness of this aerothermodynamics barrier changes with thermal and mass-diffusive effects that affect thermal entrainment. These effects, among others, depend on flow instabilities and boundary effects. These conditions lead to 
a decrease in conservation quality of food products and greater energy consumption and costs. In what concerns this topic, it must be highlighted that the ambient air infiltration load is around $67 \%$ to $77 \%$ of ORDC cooling load as exposed by Gaspar et al. [5]. The thermal entrainment of hot ambient air in empirical recirculating air curtains is due to inbalance of air distribution between discharge air grille (DAG) and perforated backpanel (PBP), and consequently to air curtain temperature, velocity, and thickness values as described by D'Agaro et al. [6] and Gray et al. [7]. Also, refrigerated air leakage from the bottom part of the frontal opening (cold leg effect) increases the energy loss to surroundings. Those facts, with the remaining heat gain components [1], lead to an increase of thermal load and consequently higher energy consumption. ASHRAE [8] points out that thermal load reduction is the first step for a better energy efficiency of refrigeration equipments that may be accomplished by air curtain optimization, reducing the thermal entrainment with ambient air, as well as the temperature of air returned to the evaporator. Therefore, most of research in this field, both experimental and numerical, to evaluate the thermal performance of ORDC focus on air curtain. Due to similarity, the research on nonrecirculating air curtains is helpful. It is mainly related with heat and mass transfer studies, considering the impinging jet of several angles, different initial velocities, temperatures and thicknesses, and generation/suppression of turbulence inside air stream [9-14]. Although, due to specific characteristics of air curtains installed in ORDC, researchers carried out two- (2D) and three- (3D) dimensional computational fluid dynamics (CFD) parametric studies. Cortella et al. [15] and Navaz et al. [16] evaluated the influence of DAG velocity in thermal performance, quantifying the air infiltration through the frontal opening. Axell and Fahlén [17] developed a CFD-parametric study to evaluate the influence of air curtain height/width ratio and inlet velocity on the thermal performance. Navaz et al. [18] evaluated the optimum operating condition based on entrained air amount, taking into account the jet width and velocity and inlet turbulence intensity. Foster et al. [19] developed 3D CFD models to analyse the effect of changing size and position of the evaporator coil, width and angle of DAG, and inserting baffle plates into the upper duct. D’Agaro et al. [6] carried out 2D and 3D CFD-parametric studies to evaluate the influence of: longitudinal ambient air movement; display cabinet length, and air curtain temperature on the extremity effects and how it reflects on ORDC performance. Chen [20] developed CFD-parametric studies to evaluate the thermal barrier performance of air curtains, adjusting the length/width ratio and its discharge angle, the height/depth ratio of the cavity, and the dimension and position of shelves. Ge and Tassou [21] developed correlations for heat transfer across air curtain with reasonable agreement with experimental data in steady-state conditions. Ge et al. [22] developed an ORDC model integrating CFD and cooling coil models. The airside inputs of the cooling coil model are the outputs of the CFD model, and, inversely, the airside outputs from the cooling coil model are used to update the boundary conditions of the CFD model. The use of the validated integration model of the ORDC allows several analyses such as the optimal designs of the geometrical structures of ORDC, curtains and coils, and further of alternative control strategies and operating states. However, this type of simulation is computationally expensive.

Other research works were just experimental, such as the study developed by Chen and Yuan [23] to evaluate the influence of ambient air temperature and relative humidity, indoor airflow, DAG velocity, PBP airflow, and nightcovers application, on the performance of an ORDC. Gray et al. [7] also conducted an experimental study to evaluate the effect of perforation pattern of PBP on the airflow distribution. Among the experimental techniques used by researchers are thermocouple thermometry, hot-wire/film anemometry, laser Doppler anemometry, digital particle image velocimetry, hygrometry, tracer gases, and infrared thermography. Other method that can be used to evaluate the thermal performance of an ORDC, based on the thermal barrier provided by the air curtain, consists in the thermal entrainment factor (TEF) calculation [6, 18, 23, 24]. This formulation was adopted by Gaspar et al. [5] to evaluate air curtain TEF for different environmental conditions (air temperature, relative humidity and velocity, magnitude, and direction) and how it influences the thermal performance of the ORDC.

The experimental techniques described above are reliable and provide results with a high degree of confidence, but its use is labour intensive and time consuming, involving high costs, being the results dependent on ORDC geometry, DAG parameters, and ambient air conditions. By other hand, the development of a complex simulation model requires large computational resources, being the computational results untrustworthy, until reliability and accuracy are checked by comparison with experimental data. Although the significant progress of CFD codes in geometry creation, data transfer from CAD/CAE packages, improvement of meshing tools, numerical robustness, and well-validated physical models for specific classes of physical phenomena, made them desirable in the design phase as an expedite analysis method. However, none of CFD research works cited above has modelled the several devices that make part of the refrigeration system. Hence, this study provides a detailed CFD model that combines the characteristics of aforementioned works. It considers a 2D CFD simulation of an ORDC taking into account the air flow through internal ducts, across fans, evaporator and grilles, and the thermal response of food products. The objective is to provide a complete CFD design tool for this type of equipment, allowing fast and efficient development of parametric studies devoted to predict how operational and geometrical modifications can improve the ORDC performance. This paper presents some results derived from experimental testing to define boundary conditions and to validate numerical predictions, the physical-mathematical and numerical model formulations, the CFD-modelling parameters and methodology for complete simulation of the air flow and heat transfer of an ORDC. The nonisothermal turbulent flow and temperature field characteristics are predicted, and several parametric studies to improve the ORDC performance are designed. 


\section{Experimental Testing}

2.1. Experimental Apparatus. Figure 1(a) shows the midplane cross-section of the open refrigerated display cabinet (ORDC) experimentally tested and numerically modelled on heat and mass transfers. The air is drawn by fans located in front of the evaporator. The air passing through the evaporator is cooled below the conservation temperature of the perishable products exposed in equipment's shelves. This air is convected to the rear duct, where part of it is discharged inside the conservation space at low velocity through the perforated backpanel (PBP). The other part of this air mass flow rate will supply the air curtain, which develops vertically between discharge (DAG) and return (RAG) air grilles.

The authors have already performed extensive experimentation on this ORDC model [5]. It is a self-contained system, in which the condensing unit and controls are built into the cabinet structure (beneath the cabinet, taking up the entire lower part). Its dimensions are $1900 \times 796 \times 1911 \mathrm{~mm}$ $(L \times W \times H)$. It has four shelves and a well tray, being its frontal opening height, $H_{c}, 1209 \mathrm{~mm}$ (see Figure 1(a)). The evaporator is housed under the well tray and integrated with refrigerant feed and return lines. Temperature regulation and defrosting are digitally conducted by an electronic thermostat, being the cooling system fan-assisted (four forward fans that blow air through the coil).

The experimental test was performed in a climate chamber Aralab Fitoclima 650000 EDTU. The test probes described in Table 1 and placed inside the cabinet as shown in Figure 1(b) (conservation space measuring locations (CSMLs)) and Figure 1(c) (air curtain measuring locations (ACMLs)) were connected to a data acquisition system Intab PC-Logger 3100. A probe-positioning system is used to evaluate the 3D effects of thermal entrainment on air curtain and properties variations along length and height of the conservation space [25]. The probe-positioning system was settled on each shelf of the equipment to measure air temperature, relative humidity, and velocity for three positions across the air curtain width and eight vertical cross-sections along the equipment's length. The positioning system moved the test probes in $240 \mathrm{~mm}$ increments for the $1800 \mathrm{~mm}$ length of shelves, taking $1 \mathrm{~min}$ to move between positions to reduce flow perturbation. Also, the properties values were acquired $1 \mathrm{~min}$ after reaching each position to ensure flow stabilization. The experimental results obtained with this point measuring technique along the air curtain and conservation space coordinates show a similar behaviour to the experimental results obtained by Gray et al. [7], Chen and Yuan [23], and Evans et al. [26]. It was found that the average variation of air temperature was $0.4 \mathrm{~K}$, and of air-relative humidity was $4.5 \%$ which are not particularly significant. Based in these results, the probes were distributed in the midplane of the equipment's length. In order to consolidate and extend the measurements data, a thermoanemometer AM 4003 was used to measure air temperature and velocity near DAG and RAG, at the refrigeration unit (compressor + condenser) and at several heights of PBP. Pressure loss was measured using a micromanometer Air Instruments Resources MP3KDS near inlets and outlets (DAG, RAG, and
PBP). The temperature of internal surfaces was obtained with K-type thermocouple contact probe using a digital thermometer FLUKE 51 (location n. ${ }^{\circ}$ 9). Additionally, several sets of experimental tests were performed to evaluate the influence of surrounding air in air temperature, velocity, and humidity inside the conservation space [5].

2.2. Testing Procedure and Results. The experimental testing follows the procedure defined by EN-ISO Standard 23953 [27] for test room climate class $n .{ }^{\circ} 3$, which considers air temperature $\left(T_{\mathrm{amb}}=298 \mathrm{~K}\right.$; air relative humidity, $\phi_{\mathrm{amb}}=60 \%$; air velocity magnitude, $v_{\mathrm{amb}}=0.2 \mathrm{~m} \mathrm{~s}^{-1}$, with direction parallel to the frontal opening plane of the ORDC, that is, $\theta_{\mathrm{amb}}=0^{\circ}$ ) and for M-package temperature class M1 $(272.15 \mathrm{~K} \leq$ $\left.T_{\text {prod }} \leq 278.15 \mathrm{~K}\right)$. The experimental test followed the procedure described in Gaspar et al. [5]. Table 2 contains the average values of the parameters measured during this period and their statistical parameters: maximum and minimum values, standard deviation $(\sigma)$, standard error of mean $(s)$, and variance $\left(\sigma^{2}\right)$. Notice that overall values of air temperature and relative humidity inside conservation space (probes location $n .{ }^{\circ} 0$ to $n .{ }^{\circ} 4$ ) consider the average values along equipment's length and height.

\section{Mathematical Formulation}

The turbulent air flow and nonisothermal heat transfer process are modelled by a $2 \mathrm{D}$ (length midplane neglecting extremity effects) steady-state mathematical model. The basic equations governing transport phenomena in an ORDC are continuity, momentum, and energy [28]. For application on the computational domain, the airflow modelling is coupled to products modelling, where within the latter region the convection term is neglected.

The air is considered as an ideal gas. Considering that flow can be driven by buoyancy forces in specific zones of the domain, the Boussinesq approximation is applied. Thus, density has a constant value in all solved equations, except for the buoyancy term in the momentum equation where it is determined as function of temperature differences. So, reference density is set to $\rho_{\text {ref }}=1.17 \mathrm{~kg} \mathrm{~m}^{-3}$ for the operating conditions defined by test room climate class n. 3 [27].

The energy equation is developed as function of temperature in steady state with constant specific heat. Further simplifications are accomplished neglecting viscous dissipation due to flow characteristics.

The turbulence is modelled by the RNG $k-\varepsilon$ model [29] since in previous works [30-33] its ability to model turbulence was assessed in comparison with other models (Spalart-Allmaras, $k-\Omega$, standard $k-\varepsilon$ ). The comparison of numerical results shows the applicability of $k-\varepsilon$ models type for simulation of a wide range of flows with minimum coefficients adjustment and also for its relatively simple formulation. The numerical predictions obtained with standard and RNG $k-\varepsilon$ models were similar. The latter model was used due to its constants revaluation and additional term in dissipation rate equation, to improve the precision of flow simulation. 


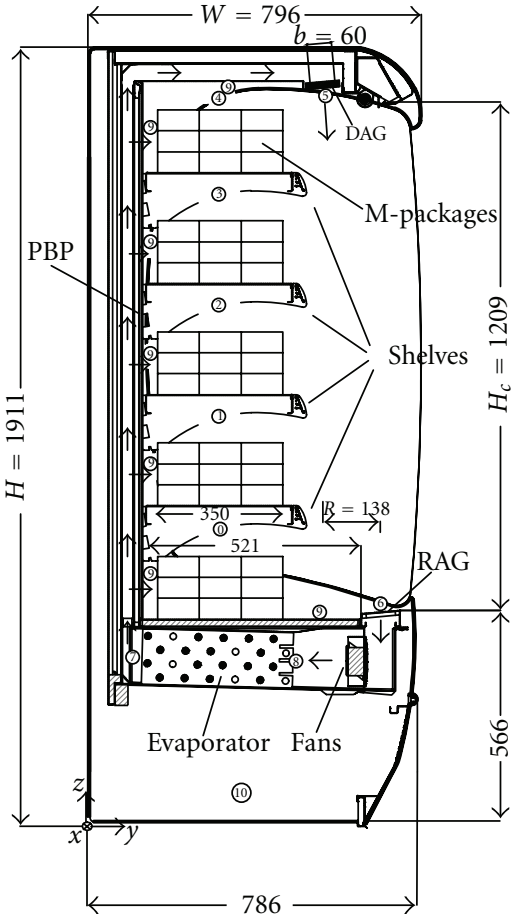

(a) Display cabinet configuration and dimensions

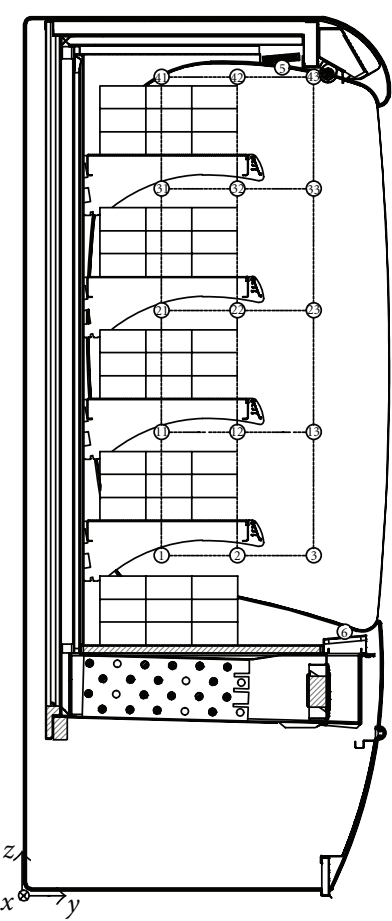

(b) Conservation space measuring locations (CSML)

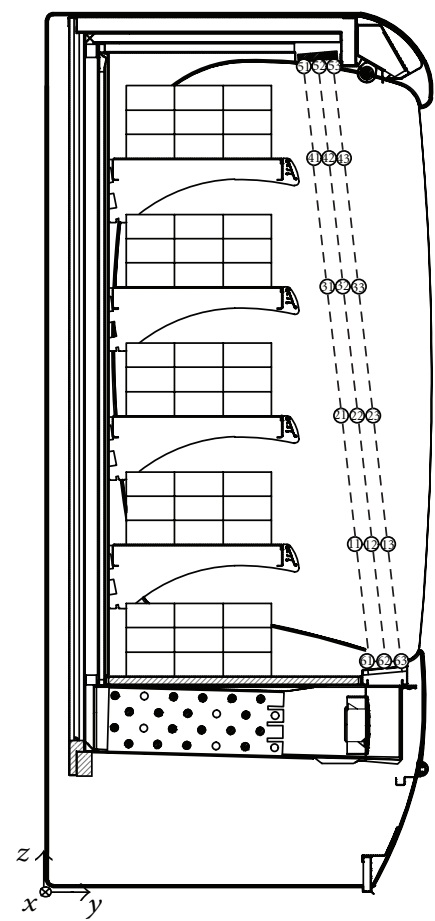

(c) Air curtain measuring locations (ACML)

FIGURE 1: Configuration of open vertical refrigerated display cabinet and measuring probes locations.

TABLE 1: Description of test probes and its location (see Figure 1(a))

\begin{tabular}{|c|c|c|c|c|c|}
\hline Loc. & Type & Accuracy & Property & Ref. & Location \\
\hline \multirow{2}{*}{$0-4$} & K-type thermocouple & $\pm 0.5 \mathrm{~K}$ & Temperature & $T_{\text {cons }}$ & \multirow{2}{*}{ Conservation space } \\
\hline & $\begin{array}{l}\text { Hygrometer (odd } \\
\text { measuring locations) }\end{array}$ & $\pm 3 \%$ & Relative humidity & $\phi_{\text {cons }}$ & \\
\hline \multirow{3}{*}{5} & K-type thermocouple & $\pm 0.5 \mathrm{~K}$ & Temperature & $T_{\mathrm{DAG}}$ & \multirow{3}{*}{ DAG } \\
\hline & Hot-wire anemometer & $\pm 0.1 \mathrm{~m} \mathrm{~s}^{-1}( \pm 10 \%)$ & Velocity & $v_{\mathrm{DAG}}$ & \\
\hline & Hygrometer & $\pm 3 \%$ & Relative humidity & $\phi_{\mathrm{DAG}}$ & \\
\hline \multirow{3}{*}{6} & K-type thermocouple & $\pm 0.5 \mathrm{~K}$ & Temperature & $T_{\text {RAG }}$ & \multirow{3}{*}{ RAG } \\
\hline & Hot-wire anemometer & $\pm 0.1 \mathrm{~m} \mathrm{~s}^{-1}( \pm 10 \%)$ & Velocity & $v_{\mathrm{RAG}}$ & \\
\hline & Hygrometer & $\pm 3 \%$ & Relative humidity & $\phi_{\mathrm{RAG}}$ & \\
\hline 7 & K-type thermocouple & $\pm 0.5 \mathrm{~K}$ & Temperature & $T_{\text {evap,out }}$ & Evaporator outlet* \\
\hline 8 & $\begin{array}{l}\text { K-type thermocouple } \\
\text { (contact) }\end{array}$ & $\pm 0.5 \mathrm{~K}$ & Temp. (surface) & $T_{\text {evap,in }}$ & Evaporator inlet* \\
\hline 9 & $\begin{array}{l}\text { K-type thermocouple } \\
\text { (contact) }\end{array}$ & $\pm 0.5 \mathrm{~K}$ & Temp. (surface) & $T_{\text {surf }}$ & Interior surfaces \\
\hline 10 & Ammeter (Clamp-on) & $\pm 0.02 \mathrm{~A}( \pm 2 \%)$ & Electric current & $I$ & Power source \\
\hline
\end{tabular}

$*$ The surface temperature of the air side-wall pipe is measured at the evaporator inlet while at the outlet is measured the air temperature.

The set of model equations is suitable for fully turbulent flow. To account for viscous effects and high gradients in proximity of walls, the turbulence model equations are used in conjunction with empirical wall functions. The complete description and implementation details of wall functions in turbulence models can be found in Rodi [34] and Launder and Spalding [35].

The influence of ambient air-relative humidity is considered by making use of a species transport model. The fluid is considered as a mixture of dry bulb air and water 
TABLE 2: Experimental average results for climatic class n. ${ }^{\circ}$ 3-EN-ISO std. 23953.

\begin{tabular}{lccccccccccccc}
\hline Parameter & $T_{\text {cons }}$ & $\phi_{\text {cons }}$ & $T_{\text {DAG }}$ & $\phi_{\text {DAG }}$ & $v_{\text {DAG }}$ & $T_{\text {RAG }}$ & $\phi_{\text {RAG }}$ & $v_{\text {RAG }}$ & $T_{\text {evap }_{\text {out }}}$ & $T_{\text {evap in }}$ & $I$ \\
\hline Unit & $\mathrm{K}$ & $\%$ & $\mathrm{~K}$ & $\%$ & $\mathrm{~m} \mathrm{~s}^{-1}$ & $\mathrm{~K}$ & $\%$ & $\mathrm{~m} \mathrm{~s}^{-1}$ & $\mathrm{~K}$ & $\mathrm{~K}$ & $\mathrm{~A}$ \\
\hline Mean value & 277.1 & 86.2 & 276.0 & 82.4 & 1.5 & 282.4 & 88.1 & 1.7 & 272.1 & 272.3 & 8.7 \\
$\sigma$ & 0.5 & 1.9 & 1.1 & 4.8 & $3.0 \times 10^{-2}$ & 0.6 & 2.2 & $9.0 \times 10^{-2}$ & 1.1 & 2.4 & 2.9 \\
$\sigma^{2}$ & 0.3 & 3.8 & 1.1 & 23.1 & $0.6 \times 10^{-3}$ & 0.4 & 4.9 & $7.2 \times 10^{-3}$ & 1.3 & 5.9 & 8.1 \\
$s$ & $3.0 \times 10^{-2}$ & $7.0 \times 10^{-2}$ & $6.0 \times 10^{-2}$ & $4.0 \times 10^{-2}$ & $1.4 \times 10^{-3}$ & $4.0 \times 10^{-2}$ & $1.0 \times 10^{-2}$ & $4.8 \times 10^{-3}$ & $6.0 \times 10^{-2}$ & $1.0 \times 10^{-2}$ & $2.0 \times 10^{-2}$ \\
Min. value & 275.8 & 82.5 & 274.8 & 68.6 & 1.1 & 280.7 & 82.9 & 1.1 & 270.0 & 270.3 & 0.3 \\
Max. value & 278.2 & 98.4 & 287.3 & 99.5 & 1.6 & 284.6 & 92.7 & 1.9 & 276.4 & 289.0 & 8.9 \\
\hline
\end{tabular}

vapour. The heat gain of ORDC by thermal radiation is one of most important cooling load components [5]. A surfaceto-surface radiation model (based in surfaces view factors calculation) is used to take this heat gain component into account.

\section{Numerical Model}

The mathematical model is a set of coupled nonlinear partial differential equations, describing mass, momentum, and energy conservation which can be simultaneously and interactively solved. The equations set was solved using the pressure-based, nonstructured grid, finite volume method CFD code FLUENT.

4.1. Geometry and Computational Mesh. The 2D geometry closely follows a mid-cross-section of ORDC. An automatic orthogonal unstructured mesh generator (Gambit) was used to develop the computational grid. The mesh was refined in the internal ducts, near fans, evaporator, DAG, and RAG vicinities and across air curtain, where velocity and temperature gradients are expected to be higher. The grid size was refined to predict accurately heat transfer by conduction inside the conservation products. Grid dependence tests were carried out for models with different grid size, that is, increasing number of control volumes (cells): (a) 17939 cells, (b) 72350 cells, (c) 110029 cells, and (d) 350533 cells. From the comparison with experimental results, the computational mesh of model (c) provides numerical results independent of grid size both in solid and fluid regions. The computational domain, grid, and boundary conditions location are shown in Figure 2. Notice that connected but independent mesh zones were defined near DAG, RAG, fans, evaporator, and internal ducts in order to speed up the process of developing future parametric studies of geometrical and/or functional modifications and the analysis of their influence on the ORDC overall performance.

4.2. Discretization of the Partial Differential Equations. The computational procedure is based on a numerical iterative process using the pressure-implicit with splitting of operators (PISOs) algorithm [36] for pressure-velocity coupling. This algorithm was derived from semi-implicit method for pressure-linked equations (SIMPLEs) algorithm [37], but it has higher performance, and it is more efficient as described by Jang et al. [38].

The equations were discretized in the control volume form using MUSCL differencing scheme. The monotone upstream-centered schemes for conservation laws (MUSCLs) scheme proposed by Van Leer [39], derives from central differencing scheme (CDS) and second-order upwind (SOU) differencing scheme) as described by Patankar [37]. It is a differencing scheme with low numerical diffusion; that is, it shows higher spatial precision for all types of computational grids and for complex flows. In this study, the comparison with experimental results shows that numerical predictions computed with MUSCL scheme are more realistic and precise. The models run on a server Intel Xeon DualCore $2.33 \mathrm{GHz}$ (4 MBytes internal cache) with 16 GBytes RAM.

4.3. Boundary Conditions. Boundary conditions (BCs) of common practice in numerical simulations, defined for climatic class n. ${ }^{\circ} 3$ of EN-ISO Standard 23953 [27], are imposed in the computational domain.

4.3.1. Ambient Boundary Condition. The ambient boundary is simulated by an "opening" type BC, that is, a constant pressure boundary which allows both inflow and outflow. The pressure value is considered to be the total pressure based on the normal component of the velocity when flow enters the domain and static pressure when it leaves the domain. The ambient air temperature is supposed to be $T_{\mathrm{amb}}=298.15 \mathrm{~K}$, and the water vapour mass fraction for $\phi_{\mathrm{amb}}=60 \%$ is $Y_{v, \mathrm{amb}}=11.80 \mathrm{~g}_{\mathrm{v}} \mathrm{kg}_{\mathrm{m}}^{-1}$. The radiative black body temperature is assumed to be $T_{\mathrm{bb}}=298.15 \mathrm{~K}$ for the algebraic calculation of radiative view factors as described by Modest [40]. A black body emissivity value $(\varepsilon=1)$ is assumed in this BC.

Free stream values for turbulent kinetic energy and its dissipation rate are assumed on the free boundary at this fixed-pressure condition set in terms of turbulence intensity, $I_{t}=10 \%$, (the worst situation considers the effects of consumers passage in front of equipment, of air-conditioning system operation and the influence of pressure perturbations) and hydraulic diameter of equipment's frontal opening to ambient, $D_{h}=1.2 \mathrm{~m}$, as being the characteristic turbulence length scale. The values of parameters specified at fixed pressure $\mathrm{BC}$ are shown in Table 3.

The influence of the distance at which this free boundary is defined is not consensual as it affects the predicted 


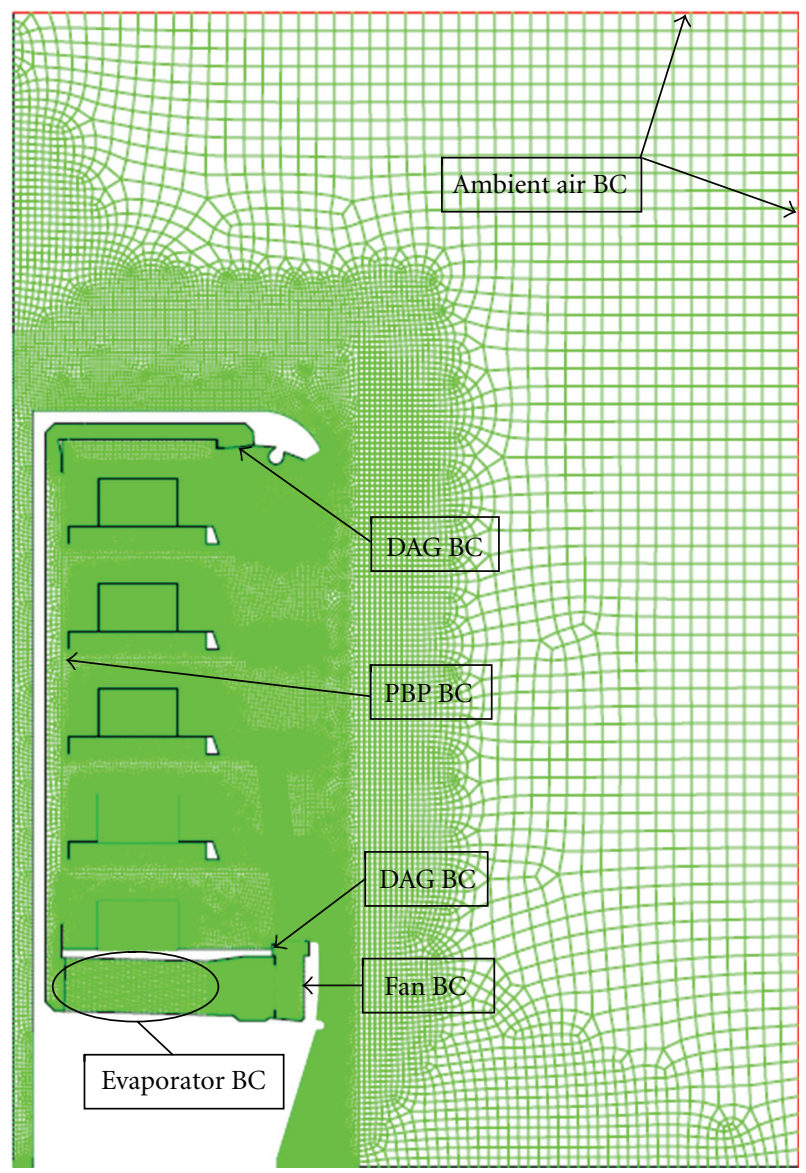

FIgURE 2: Computational model geometry and grid, and boundary conditions location.

solutions. The numerical studies of ORDC developed by Cortella et al. [15], and George and Buttsworth [41] consider this $\mathrm{BC}$ at $2 / 3$ and $5 / 4$, respectively, of the equipment width. Bhattacharjee and Loth [9] stated that this $\mathrm{BC}$ should be imposed far away from zone of interest in the computational domain, likewise at a distance of $40 b$, being $b$ the air curtain width. Gaspar et al. [42] tested different distances of this free $\mathrm{BC}$ to ascertain the effect on the numerical predictions of temperature and velocity within an ORDC. The following cases were tested: (1) $1 / 3 W$; (2) $2 / 3 W$; (3) $W$; and (4) $3 / 2 W$, being $W$ the width of the ORDC. Based on comparison between numerical predictions and experimental values, the precision of numerical results increases with the distance at which is defined the BC. Thus, the fixed pressure $\mathrm{BC}$ was defined at a distance equal to $3 / 2 W$ from the frontal opening of the equipment since it allows modelling the flow with heat and mass transfers more precisely.

\subsubsection{Wall Boundary Condition}

(1) Shear Boundary Condition. Wall boundary conditions are used to bound fluid and solid regions. At the walls a nonslip BC (zero velocity) is considered.
TABLE 3: Values imposed at the fixed pressure boundary condition.

\begin{tabular}{lccc}
\hline Parameter & Variable & Unit & Value \\
\hline Relative pressure & $p$ & $\mathrm{~Pa}$ & 0.00 \\
Temperature & $T_{\mathrm{amb}}$ & $\mathrm{K}$ & 298.15 \\
Turbulence intensity & $I_{t}$ & $\%$ & 10.00 \\
Hydraulic diameter & $D_{h}$ & $\mathrm{~m}$ & 1.20 \\
Black body temperature & $T_{\mathrm{bb}}$ & $\mathrm{K}$ & 298.15 \\
Emissivity & $\varepsilon$ & - & 1.00 \\
Water vapour mass fraction & $Y_{v}$ & $\mathrm{~g}_{\mathrm{v}} \mathrm{kg}_{\mathrm{m}}^{-1}$ & 11.80 \\
\hline
\end{tabular}

\section{(2) Thermal Boundary Conditions}

Heat Flux Boundary Conditions. An adiabatic BC is defined for walls not considered in heat transfer calculation. However, a heat flux BC is used to simulate heat generated by the illumination (85\% for fluorescent lamp OSRAM L58W/20) and heat flux through conduction across material layers that compose the equipment walls. The heat flux across them is determined by Fourier Law using a global heat transfer coefficient determined by the conductive thermal resistances of each wall material. The experimental values of surface temperature on the internal and external sides of the 
TABLE 4: Walls heat flux boundary condition.

\begin{tabular}{lccc}
\hline Surfaces & Variable & Unit & Value \\
\hline $\begin{array}{lcc}\text { Illumination (OSRAM L58W/20) } \\
\text { Interior surfaces of the equipment }\end{array}$ & $\dot{q}_{\text {ilum }}$ & $\mathrm{W} \mathrm{m}^{-2}$ & 10.00 \\
$\quad$ & & \\
Top & $\dot{q}_{\text {duct, top }}$ & $\mathrm{W} \mathrm{m}^{-2}$ & 6.08 \\
Rear & $\dot{q}_{\text {duct, rear }}$ & $\mathrm{W} \mathrm{m}^{-2}$ & 7.63 \\
Bottom (well tray) & $\dot{q}_{\text {duct, bottom }}$ & $\mathrm{W} \mathrm{m}^{-2}$ & 6.96 \\
\hline
\end{tabular}

TABLE 5: Tylose (equivalent solid food products) thermal characteristics.

\begin{tabular}{lccc}
\hline Parameters & Variable & Unit & Value \\
\hline Density & $\rho$ & $\mathrm{kg} \mathrm{m}^{-3}$ & $1.11 \times 10^{3}$ \\
Specific heat $\left(T>T_{\text {cong }}\right)$ & $C_{p 1}$ & $\mathrm{~kJ} \mathrm{~kg}^{-1} \mathrm{~K}^{-1}$ & 3.70 \\
Thermal conductivity $(279.15 \mathrm{~K})$ & $k$ & $\mathrm{~W} \mathrm{~m}^{-1} \mathrm{~K}^{-1}$ & 0.39 \\
\hline
\end{tabular}

equipment are used. Table 4 shows the heat flux values fixed as BC.

Species Boundary Conditions. A zero-gradient condition for water vapour mass fraction is assumed at walls.

Radiation Boundary Conditions. It is necessary to specify the emissivities of different surfaces to use a surface-tosurface radiation model. Constant emissivities are fixed for the internal surfaces of the equipment $\varepsilon_{\text {sup }}=0.9$ and for external ground, $\varepsilon_{\text {ground }}=0.7$. It is considered the black body emissivity, $\varepsilon_{\mathrm{bb}}=1$, for the external enclosure surfaces.

4.3.3. Product Load (Solid Region). Following EN-ISO Standard 23953 [27] and ISO 15502 [43], the products simulators are made of tylose, in which thermal characteristics are similar to meat. Considering values given by ASHRAE [44], the equivalent solid thermal characteristics to simulate food products are shown in Table 5.

4.3.4. Air Pressure Drop through the PBP: Porous Medium. The detailed flow simulation across perforation of the backpanel requires a very high grid refinement and consequently a huge computational effort. Thus, PBP was modelled as a porous medium to simplify the numerical model. The thickness of PBP is $1.6 \mathrm{~mm}$. The porous medium is composed by 520 grid cells ( 4 grid cells along thickness and 130 grid cells along height): $\Delta y=0.4 \mathrm{~mm}$ and $\Delta z=20 \mathrm{~mm}$. The porous medium is modelled by the addition of a momentum source term corresponding to Forchheimer law to the standard fluid flow equations [45]. The source term is composed of two components: a viscous loss term (Darcy's law, the first term on the right-hand side of (1)), and an inertial loss term (the second term on the right-hand side of (1)) due to high flow velocities [45] and low thickness to hole diameter ratio [46]. We have

$$
S_{i}=-\left(\frac{\mu}{k} v_{i}\right)-\left(C_{2} \frac{1}{2} \rho\left|v_{i}\right| v_{i}\right) .
$$

TABLE 6: PBP parameters: porous medium.

\begin{tabular}{lccc}
\hline Parameters & Variable/Expression & Unit & Value \\
\hline Porosity & $\varepsilon=V_{v} / V_{t}$ & - & $2.60 \times 10^{-2}$ \\
Permeability & $k=\varepsilon D_{\text {hole }}^{2} / 12$ & $\mathrm{~m}^{2}$ & $4.91 \times 10^{-8}$ \\
$\begin{array}{l}\text { Viscous resistance } \\
\text { coefficient }\end{array}$ & $k_{x}^{-1}$ & $\mathrm{~m}^{-2}$ & $2.56 \times 10^{7}$ \\
$\begin{array}{l}\text { Loss coefficient } \\
\begin{array}{l}\text { Inertial resistance } \\
\text { coefficient }\end{array}\end{array}$ & $K[49]$ & - & 8.65 \\
\hline
\end{tabular}

In (1), $v$ is the average value of fluid velocity through the surface normal to flow, $k$ is the medium permeability, and $C_{2}$ is the inertial resistance factor. The permeability of perforated surfaces is defined by Bear [45] and Tang et al. [47], in which the thickness of the porous medium, $\delta$, has an analogical correspondence to the perforation diameter, $D_{\text {hole }}$ as described in (2). We have

$$
k=\frac{\varepsilon \delta^{2}}{12},
$$

where $\varepsilon$ is the porosity (void fraction), that is, the volume fraction of fluid within the porous region (i.e., the open volume fraction of the medium) given by the ratio between the open volume and total volume of porous medium (see (3)). One finds that

$$
\varepsilon=\frac{V_{v}}{V_{t}}=1-\frac{V_{s}}{V_{t}} .
$$

The constant value parameter $C_{2}$ provides a correction for inertial losses in porous medium. This constant can be viewed as a loss coefficient per unit length along flow direction, thereby allowing the pressure drop to be specified as a function of dynamic head (see (4)). As this factor is specified for fully open porous cells, the loss coefficient, $K$, must be converted into dynamic head loss, considering the same flow rate per unit length of porous region $[48,49]$. So we have

$$
C_{2}=\frac{K}{\delta}\left(\frac{v_{p}}{v_{0}}\right)^{2}=\frac{K}{\delta}\left(\frac{1}{\varepsilon}\right)^{2},
$$

where $v_{0}$ and $v_{p}$ are respectively the fluid velocities of the fully open porous medium and of flow passage through the porous medium. The loss coefficient is calculated as proposed by Idel'Cik [50]. The values imposed at PBP are shown in Table 6.

4.3.5. Air Pressure Drop through DAG and RAG: Porous Medium Model Simplification. The air pressure drop is experimentally measured at DAG and RAG. Equation (5) represents a one-dimensional simplification of the porous media model defined at the faces that simulate these grilles. The thin porous medium has a finite thickness, $\delta$, over which the pressure change is defined as a combination of Darcy's Law and Forchheimer inertial loss term. We obtain that

$$
\Delta p=-\left(\frac{\mu}{k} v+C_{2} \frac{1}{2} \rho v^{2}\right) \delta .
$$


The fixed parameters on these $\mathrm{BC}$ based in geometrical characteristics of grilles and experimental measures of air temperature and relative humidity are shown in Table 7.

4.3.6. Heat and Mass Transfer and Pressure Drop Modelling across the Evaporator. The ORDC contains a wavy fin and tube heat exchanger (evaporator). At the evaporator, it is specified a heat exchanger $\mathrm{BC}$ type in which are defined both pressure drop and heat transfer coefficient as functions of velocity in direction normal to the heat exchanger. The $\mathrm{BC}$ is specified at an infinitely thin face, and the pressure drop through the heat exchanger is assumed to be proportional to the dynamic head of the fluid. The friction factor, $f=0.0078$, is calculated through the empirical correlation (6) proposed by Wang et al. [51]. We have

$$
\begin{aligned}
f= & 0.05273 \operatorname{Re}_{D c}^{f 1}\left(\frac{P_{d}}{X_{f}}\right)^{f 2}\left(\frac{F_{p}}{P_{t}}\right)^{f 3} \\
& \times\left[\ln \left(\frac{A_{0}}{A_{t}}\right)\right]^{-2.726}\left(\frac{D_{h}}{D_{c}}\right)^{0.1325} N_{t l}^{0.02305}, \\
f 1= & 0.1714-0.07372\left(\frac{F_{p}}{P_{l}}\right)^{0.25} \ln \left(\frac{A_{0}}{A_{t}}\right)\left(\frac{P_{d}}{X_{f}}\right)^{-0.2}, \\
f 2= & 0.426\left(\frac{F_{p}}{P_{t}}\right)^{0.3} \ln \left(\frac{A_{0}}{A_{t}}\right), \\
f 3= & \frac{-10.2192}{\ln \left(\operatorname{Re}_{D c}\right)}
\end{aligned}
$$

The pressure drop, $\Delta p=8.33 \mathrm{~Pa}$, is calculated by (7) proposed by Kays and London [52], being contraction, $K_{c}$, and expansion, $K_{e}$, loss coefficients given by McQuiston and Parker [53]. We have

$$
\begin{aligned}
\Delta p=\frac{G^{2}}{2 \rho_{\text {in }}}\left[f \frac{A_{0}}{A_{c}}\left(\frac{\rho_{\text {in }}}{\rho_{m}}\right)+\left(K_{c}+1-\sigma^{2}\right)\right. & \\
& \left.+2\left(\frac{\rho_{\text {in }}}{\rho_{\text {out }}}-1\right)-\left(1-\sigma^{2}-K_{e}\right) \frac{\rho_{\text {in }}}{\rho_{\text {out }}}\right] .
\end{aligned}
$$

The heat transfer modelling through a heat exchanger $\mathrm{BC}$ type in the CFD code requires the specification of overall heat transfer coefficient, $U$, and refrigerant (R404A)

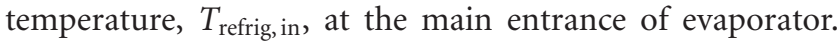
The variation of refrigerant temperature across evaporator (with phase change process) is reduced [54], so its value can be considered constant. It is assumed no superheating of refrigerant, and all heat transfer is on the two-phase zone at constant temperature. The value determined for the overall heat transfer coefficient, $U=124.16 \mathrm{~W} \mathrm{~m}^{-2} \mathrm{~K}^{-1}$, is referred to the air temperature downstream of heat exchanger, $T_{a \text {, out }}$. Based in the equation of energy conservation and considering the experimental values of air properties upstream and downstream the heat exchanger, the value of refrigerant temperature at heat exchanger entrance, $T_{\text {refrig, in }}=271.05 \mathrm{~K}$, is determined by a trial and error-iterative procedure. These parameter values are based in the heat balance of the evaporator, determined with the average experimental values.

The heat flux from heat exchanger to surrounding fluid, $\dot{q}_{\text {evap }}=124.31 \mathrm{~W} \mathrm{~m}^{-2}$, is determined by (8). Taking into account the total surface area of the evaporator, $A_{0}$, this value is consistent with the ORDC's cooling load determined by Gaspar et al. [5]. We have

$$
\dot{q}_{\text {evap }}=\frac{\dot{m} C_{p}}{A_{0}}\left(T_{a, \text { in }}-T_{a, \text { out }}\right)=U\left(T_{a, \text { out }}-T_{\text {refrig, in }}\right) .
$$

However, since the evaporator is modelled as an infinitely thin $\mathrm{BC}$, it is necessary to obtain the equivalent heat flux based on surface areas ratio given by (9). We obtain that

$$
\dot{q}_{\mathrm{eq}}=\frac{A_{0}}{A_{\mathrm{eq}}} \dot{q}_{\mathrm{evap}}=9414 \mathrm{~W} \mathrm{~m}^{-2} .
$$

The determined equivalent overall heat transfer coefficient, $U_{\mathrm{eq}}=910.42 \mathrm{~W} \mathrm{~m}^{-2} \mathrm{~K}^{-1}$, is assumed to be similar to a convective heat transfer coefficient. This simplification was based on the evaluation of empirical correlations for Colburn factor and friction factor available for heat exchangers with corrugated fins.

The mass transfer modelling through a heat exchanger BC type consists in the specification of a Dirichlet BC for water vapour mass fraction, considering the air dehumidification process. By psychometric analysis, the water vapour mass fraction specified at evaporator exit is $Y_{v}=$ $3.3722 \mathrm{gv} \mathrm{kg}_{\mathrm{m}}{ }^{-1}$.

4.3.7. Fan Boundary Condition Modelling the Pressure Rise across the Fan. A discontinuous pressure rise across fans (infinitely thin face) is specified as a function of air velocity. The empirical characteristic curve which governs the relationship between head (pressure rise) and flow rate (velocity) across a fan element (obtained at the manufacturer: EBM Papst series 4500) is converted into a 4th-order polynomial relationship (10) and specified as BC. We obtain that

$$
\Delta p=-1.61 v^{4}-2.67 v^{3}+22.7 v^{2}-51.1 v+79.2 .
$$

4.4. Solution Monitoring and Control Techniques. The linear relaxation method is used to reduce high variation of dependent variables during the iterative process of calculation. Linear relaxation values ranged from 0.3 for pressure to 0.8 for momentum. The convergence monitoring was done by the sum analysis of absolute residuals of mean field variables. The iterative procedure run until a prescribed convergence criterion for absolute residuals $\left(\lambda \leq 12 \times 10^{-4}\right)$ is met.

\section{Results and Discussion}

The CFD modelling of air flow and thermal patterns inside the conservation space of a vertical ORDC has an operation temperature varying from $273.15 \mathrm{~K}$ to $278.15 \mathrm{~K}$. This type of equipment design still requires studies due to the major influence of the frontal ambient opening on the heat and mass transfers.

The numerical simulations allow the evaluation of air temperature, relative humidity, and velocity distributions within the equipment in order to propose possible paths for technical evolution. Only most significant results concerning 
TABLE 7: DAG and RAG porous medium parameters.

\begin{tabular}{|c|c|c|c|c|}
\hline Grille & Parameters & Variable/expression & Unit & Value \\
\hline \multirow{5}{*}{ RAG } & Pressure loss & $\Delta p$ (experimental value $)$ & $\mathrm{Pa}$ & 2.30 \\
\hline & Porosity & $\varepsilon=V_{v} / V_{t}$ & - & 0.51 \\
\hline & Permeability & $k=\varepsilon D_{h}^{2} / 12$ & $\mathrm{~m}^{2}$ & $4.24 \times 10^{-6}$ \\
\hline & Loss coefficient & $K=2 \Delta p / \rho v^{2}$ & - & 1.33 \\
\hline & Inertial resist. coef. & $C_{2}=(K / \delta)(1 / \varepsilon)^{2}$ & $\mathrm{~m}^{-1}$ & $5.34 \times 10^{3}$ \\
\hline \multirow{5}{*}{ DAG } & Pressure loss & $\Delta p$ (experimental value $)$ & $\mathrm{Pa}$ & 0.30 \\
\hline & Porosity & $\varepsilon=V_{v} / V_{t}$ & - & 0.72 \\
\hline & Permeability & $\begin{array}{c}k=\varepsilon D_{h}^{2} / 32=\varepsilon \\
\left(4 \cdot\left(3 \sqrt{3} D_{\text {comb }}^{2} / 8\right) / 6 r\right)^{2} / 32\end{array}$ & $\mathrm{~m}^{2}$ & $2.76 \times 10^{-7}$ \\
\hline & Loss coefficient & {$[50]$} & - & 2.67 \\
\hline & Inertial resist. coef. & $C_{2}=(K / \delta)(1 / \varepsilon)^{2}$ & $\mathrm{~m}^{-1}$ & $2.15 \times 10^{2}$ \\
\hline
\end{tabular}
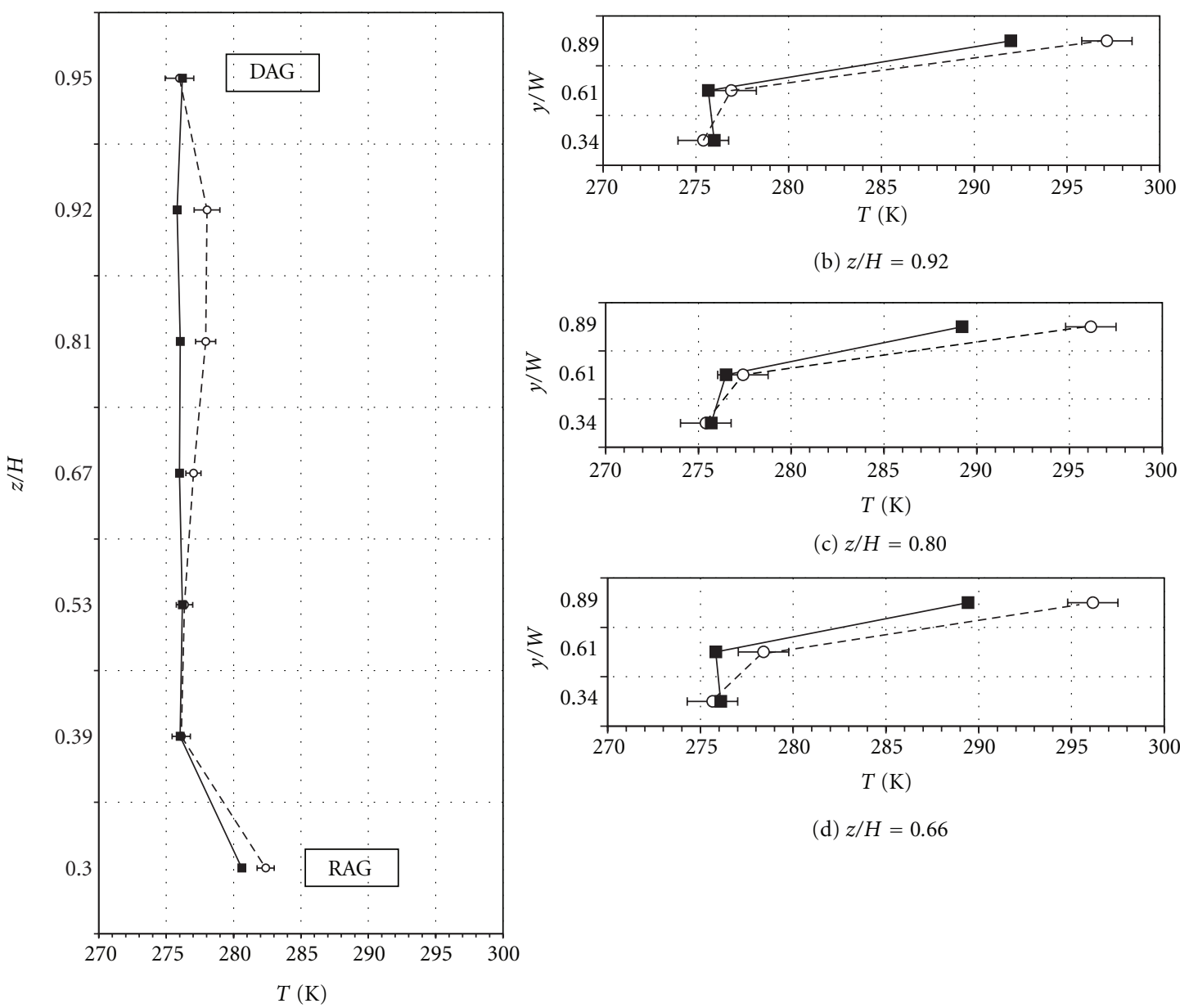

(b) $z / H=0.92$

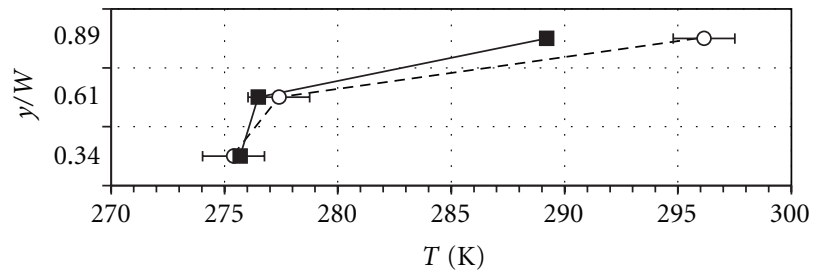

(c) $z / H=0.80$

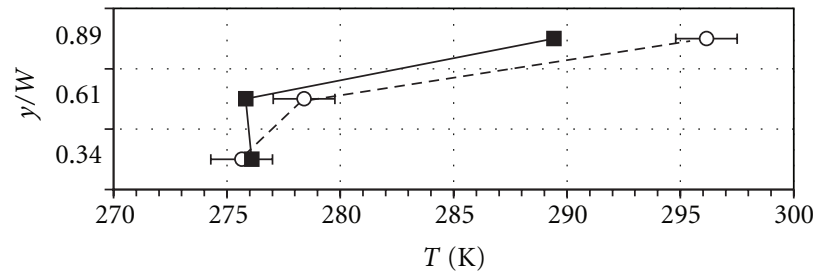

(d) $z / H=0.66$

(a) $y / W=0.38$ (exception for $(y / W)_{\mathrm{DAG}}=$ 0.72 and $\left.(y / W)_{\text {RAG }}=0.88\right)$ 


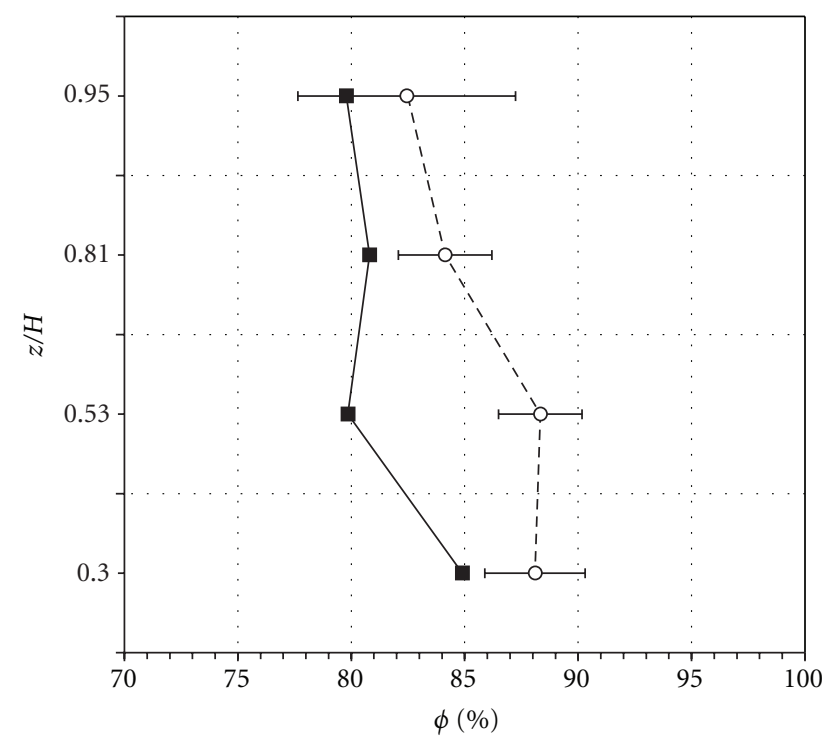

FIgURE 4: Comparative profiles of air-relative humidity, $\phi(y / W=$ $0.38, z / H)$ [\%] (see CSML in Figure 1(b)). (Legend: numerical: $\square$; experimental: $\bigcirc)$.

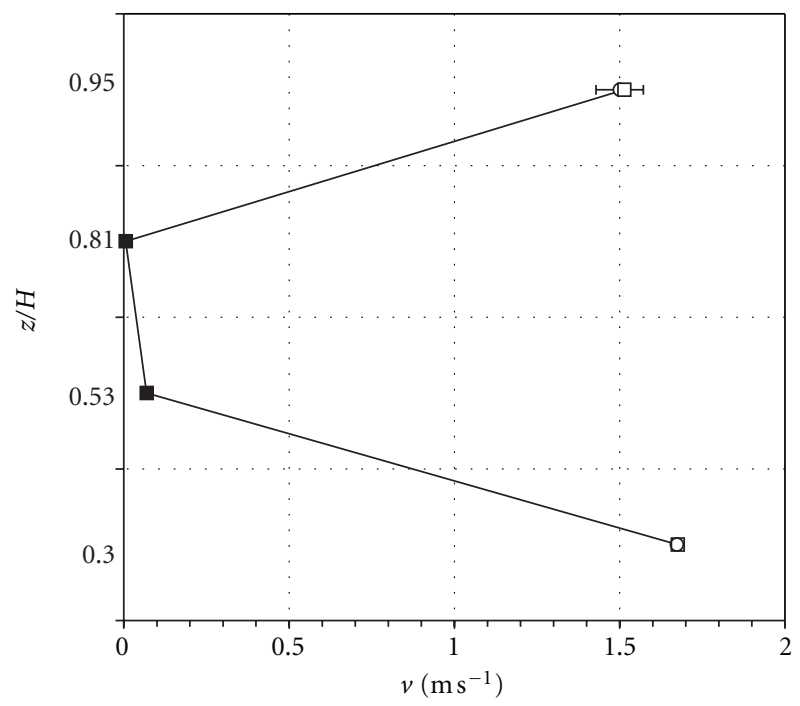

Figure 5: Comparative profiles of the air velocity, $v(y / W=0.38$, $z / H)\left(\mathrm{m} \mathrm{s}^{-1}\right)$ (see CSML in Figure 1(b)). (Legend: numerical: experimental: $\bigcirc)$.

flow properties and thermal behaviour are discussed here. The numerical predictions solution required approximately $4 \mathrm{~h} 30 \mathrm{~m}$ performing 10000 iteration sweeps.

5.1. Comparison with Experimental Data. The validation of numerical predictions of the 2D ORDC model is accomplished by its comparison with experimental measurements data.

Figures 3, 4, and 5 show the comparative profiles, for different planes, of the experimental average values of air temperature, relative humidity, and velocity. The predicted steady-state air flow and heat transfer inside the
ORDC both present a reasonable quantitative agreement. The experimental average points are represented by $\bigcirc$, and numerical predictions points are represented by $\mathbf{\square}$. For the validation points set (90 validation points), the minimum absolute deviations from experimental measures for air temperature, relative humidity, and velocity were respectively: $e_{T}(y / W=0.34, z / H=0.39)=0.08 \mathrm{~K}$ (conservation zone at 3rd shelf height $), e_{\phi}(y / W=0.52, z / H=0.88)=$ $0.26 \%$ (conservation at 4 th shelf height), and $e_{v}(y / W=0.52$, $z / H=0.88)=0.002 \mathrm{~m} \mathrm{~s}^{-1}$ (near RAG). The highest quantitative discrepancies are found outside the air curtain limits on the external ambient side $(y / W \approx 1)$, thus without relevant significance for the study.

Figure 6 shows the comparison of numerical predictions of product core average temperatures with experimental data obtained by Gill et al. [55] (ten retail stores were tested), Foster et al. [19] (difference between minimum and maximum package temperature is around $8 \mathrm{~K}$ ), Evans et al. [26] (single average temperature value for all M-packages through its standard deviation), Gray et al. [7] (ORDC with inclined shelves), and Lu et al. [56] (evaporator in the back of the cabinet and possessing two air curtains). The predictions of core products temperature are compared with results from other studies because a uniform initial value for all products core temperature was not ensured. The products core temperatures are in the range of the results obtained by the abovementioned studies.

Considering the range of air temperature, relative humidity and velocity variations measured during experimental testing, the deviation between experimental data and numerical predictions is acceptable for this type of engineering application. The nonoverlapping between experimental and numerical results is due to experimental errors (measurements precision, physical phenomena perturbation, etc.), physical-mathematical model assumptions (2D, steady state, turbulence model, PBP and evaporator formulations, open boundary BC definition, etc.), numerical model (the purpose of the MUSCL scheme is to reduce the higher-order terms to first-order eliminating instabilities. However, its use for incompressible flows can damp the physical solution in some extend, providing nonphysical predictions especially in the vicinity of mixing layers and where instabilities occur), i.e., in the air curtain (a phenomenon also observed by D'Agaro et al. [6] and Hammond et al. [57]). Nevertheless, the combined analysis of experimental data and numerical predictions shows that the computational model follows the physical phenomena occurring in the real equipment.

5.2. Numerical Results Analysis and Discussion. The numerical predictions of air flow and heat transfer for the ORDC model subjected to climatic class $n .{ }^{\circ} 3$ of EN-ISO Standard 23953 [27] are analysed in this section. This analysis will allow the development of numerical parametric studies to improve the global performance of this type of equipments.

5.2.1. Velocity Field Predictions. The numerical predictions of air velocity field are shown in Figure 7. It can be observed the main characteristics of air flow, low air velocity between 


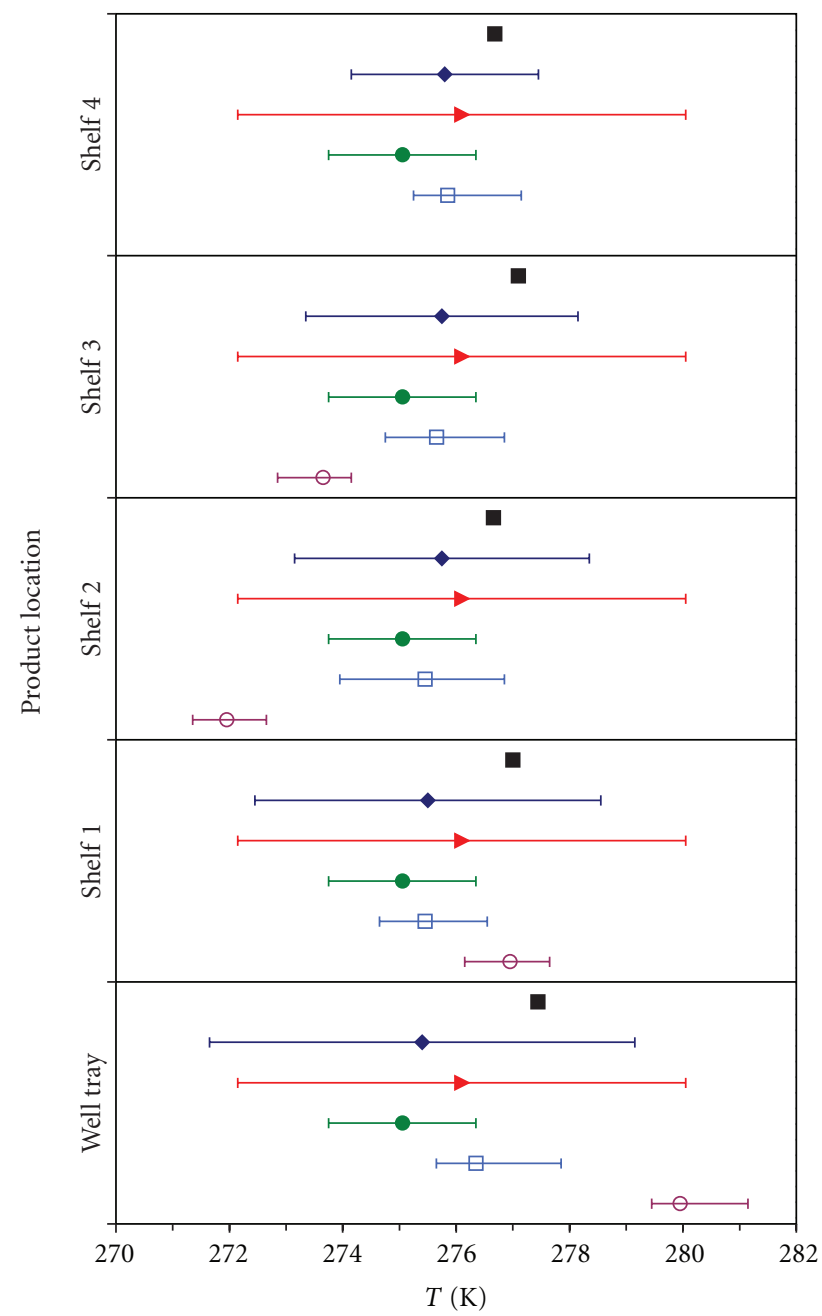

FIGURE 6: Comparative profiles of internal product temperature, $T(y / W=0.33, z / H)(\mathrm{K})$.

shelves in contrast with high velocities in ducts and at DAG exit. The thermal mixture between refrigerated air curtain and ambient is detected by the increase of air curtain thickness as it moves toward RAG.

A substantial spillage of refrigerated air to ambient can be observed in RAG vicinity due to increased mass flow rate as consequence of entrainment from air curtain. It is also related with the air curtain momentum weakening, being the air velocities quite smaller when compared to those near DAG. These effects convert into energy losses.

Flow details are analysed locally. Figure 8 shows the velocity vectors predictions near DAG and RAG. Several eddies that promote thermal mixture are predicted in DAG vicinity as shown in Figure 8(a). A parametric study where fan velocity and DAG angle influence on thermal performance are studied can provide valuable information to an improved design of the ORDC.

Some recirculations around food products are predicted, as well as the "plug flow" from PBP carrying heat towards air curtain. Other parametric study that can provide an insight about this condition is related to the PBP holes diameter and their distribution, homogeneous or not, in the panel.
The velocity vectors field near RAG is shown in Figure 8(b). Spillage to exterior ambient and eddies formation are predicted at this location. These conditions can be further analysed in a parametric study where different values of fan velocity and RAG angle are tested. Higher air velocities inside rear duct, smaller ones through PBP, and the lowest air velocities inside the conservation space are predicted. Also, vortices are predicted on duct curves, which consequently decrease the air velocity at DAG. Thus, a parametric study can be developed to analyse the inclusion of air guides or deflectors inside ducts to improve air flow by reducing friction. A recirculation region is predicted due to interaction between low velocity air in the conservation zone and high velocity of air curtain. This recirculation reduces air curtain momentum, decreasing its performance as aerothermodynamics barrier to ambient air.

5.2.2. Temperature Field Predictions. The homogeneity degree of temperature distribution in the refrigerated display space is shown in Figure 9. A temperature gradient rising along ORDC's width and height is predicted, suggesting 


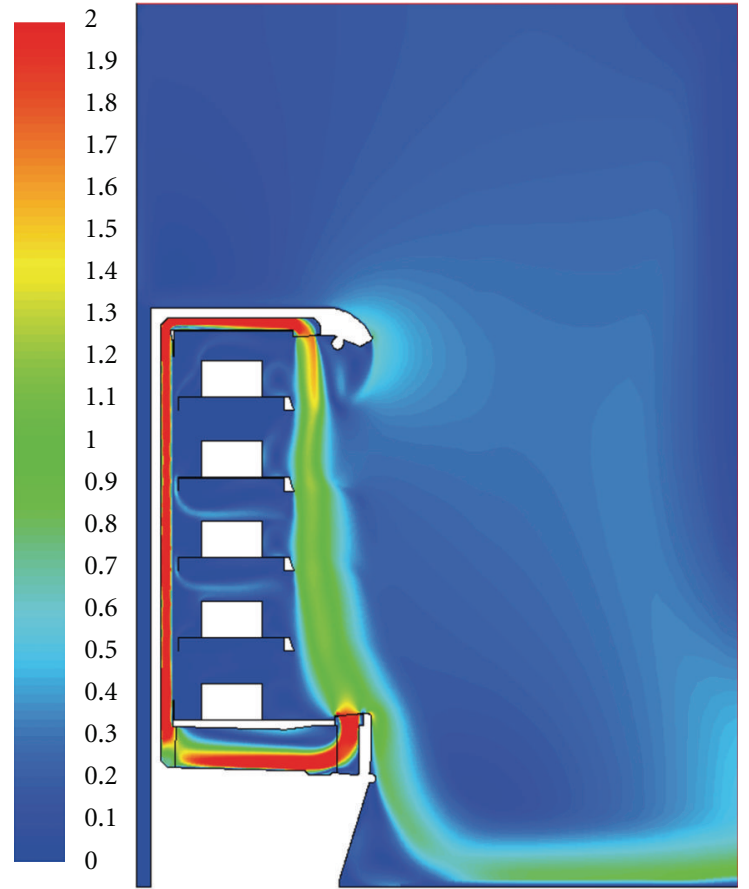

FIGURE 7: Velocity field numerical predictions for recirculated air curtain, $v\left(\mathrm{~m} \mathrm{~s}^{-1}\right)$.

that thermal entrainment occurs. The radiation heat transfer affects mostly the surfaces "viewed" from the external environment. The maximum value of air temperature is predicted in the well tray. The internal temperature of products is not constant, as products located at shelves front are more exposed to thermal entrainment through air curtain and by thermal radiation. These results are in concordance with numerical predictions obtained by Cortella [58] and with experimental results obtained by Gill et al. [55], Foster et al. [19], and Evans et al. [26].

5.2.3. Relative Humidity Field Predictions. The numerical results of air relative humidity are coherent with psychometric analysis, that is, the air-relative humidity decreases with air temperature increase. At the interface region between air curtain and ambient, the relative humidity increases due to thermal interaction promoted by eddies development.

5.2.4. Mass Flow and Heat Transfer Rates across the Air Curtain Predictions. A region that virtually encloses air curtain boundaries is considered as shown in Figure 10. These boundaries enclose five control volumes (VC). The numerical results of mass flow (11) and heat transfer (12) rates per unit length are determined for each one. One has

$$
\begin{aligned}
& \dot{m}=\rho v A\left(\mathrm{~kg} \mathrm{~s}^{-1}\right), \\
& \dot{Q}=\dot{m} C_{p} \Delta T(\mathrm{~W}) .
\end{aligned}
$$

Figures 11 and 12 show the values and directions of mass flow and heat transfer rates across air curtain per unit length. These results indicate that air curtain gains thermal energy from ambient and conservation region. The latter gains are related to thermal radiation, illumination, and heat conduction through equipment walls.

The mass flow and heat transfer rates predictions show that recirculated air curtain gains energy from external and internal borders, $\Delta \dot{Q}=411 \mathrm{~W} \mathrm{~m}^{-1}$. It gains energy from ambient at higher heights (East faces of $\mathrm{VC} \mathrm{n} .{ }^{\circ} 1,2,3$, and 4) and losses energy near RAG (East face of $\mathrm{VC} \mathrm{n.}{ }^{\circ} 5$ ) at the external border. Simultaneously, it loses energy to the conservation space (West faces of VC n. ${ }^{\circ} 1,2$, and 3) and gains it at lower heights (West faces of VC n. ${ }^{\circ} 4$ and 5). These predictions show that the air curtain is a dynamic system, gaining and losing energy, depending on air velocity, turbulence, air mass ratio between discharge grille and perforated backpanel, among other factors. An air curtain that provides full protection is an unfeasible condition in ORDC. However, the analysis of CFD predictions, such as those provided by the CFD model described along this paper, can help to improve the aerothermodynamics blockage efficacy.

\section{Conclusions}

A CFD model of an ORDC, including ducts, grilles, perforated backpanel, evaporator, and fans, has been developed to simulate air fluid flow and heat transfer. The aim of the CFD model is to cover the simulation of both air curtain and air flow inside the ducts, which is not common way of using CFD in this type of application. The main objective consists in the development of a detailed CFD model which allows an expedite simulation of design improvements aimed to increase the thermal performance and to reduce the energy consumption of ORDC.

The characterization of air flow and heat transfer allows identifying parameters that can be adjusted and hence reducing the impact of thermal entrainment and improving global performance of ORDC. The main thermal load in this type of equipments is the infiltration of ambient air. The determination of parameters that influence the overall air curtain efficacy, likewise mass flow and heat transfer rates across it, can provide valuable information to performance improvement. The progressive downward thermal entrainment into the air curtain is very dependent on the development of eddies which trigger the mixing. The momentum reduction decreases air curtain stability. This condition promotes a nonuniform air temperature distribution inside the ORDC and influences temperature differences inside the products. Also, the predicted spillage of cold air to surroundings near RAG and the temperature value at this location affect the energy performance of the equipment.

The agreement between numerical predictions and experimental results is quite good and adequate to these type of engineering problems although the authors recognize that this model can be improved to perform transient regime simulations, and the possibility of considering threedimensional effects will provide additional achievements. Nevertheless, this CFD model is suitable to investigate the 


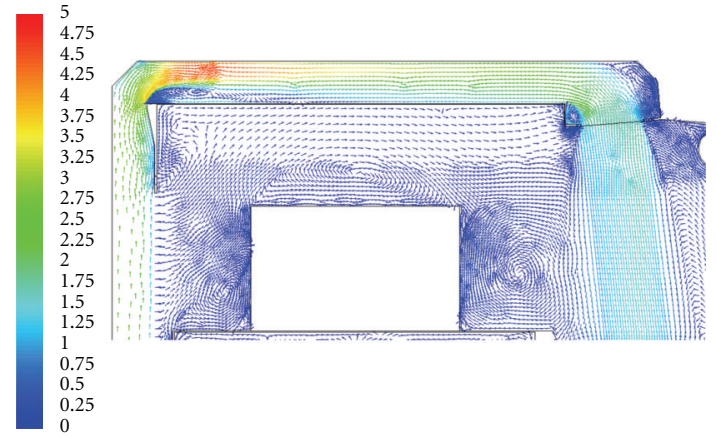

(a) DAG region, $v\left(\mathrm{~m} \mathrm{~s}^{-1}\right)$

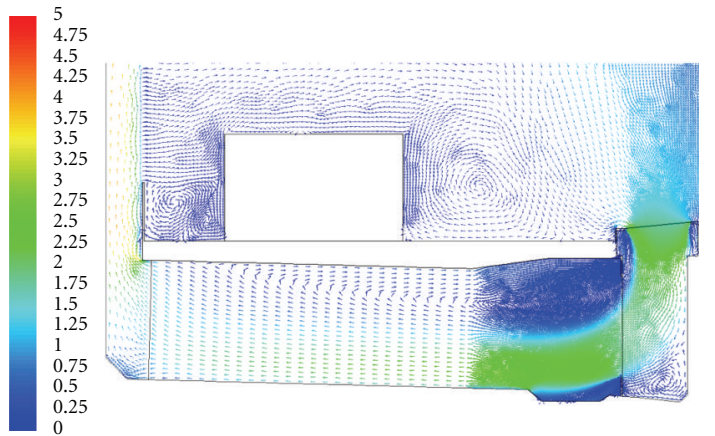

(b) RAG region, $v\left(\mathrm{~m} \mathrm{~s}^{-1}\right)$

Figure 8: Velocity vectors field numerical predictions.

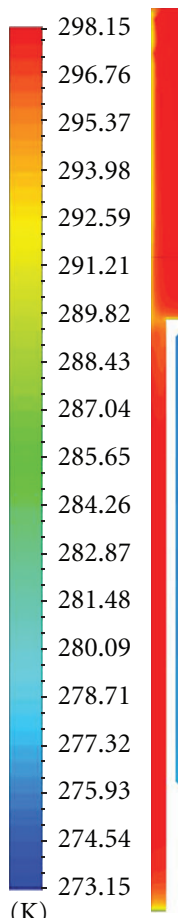

(K)
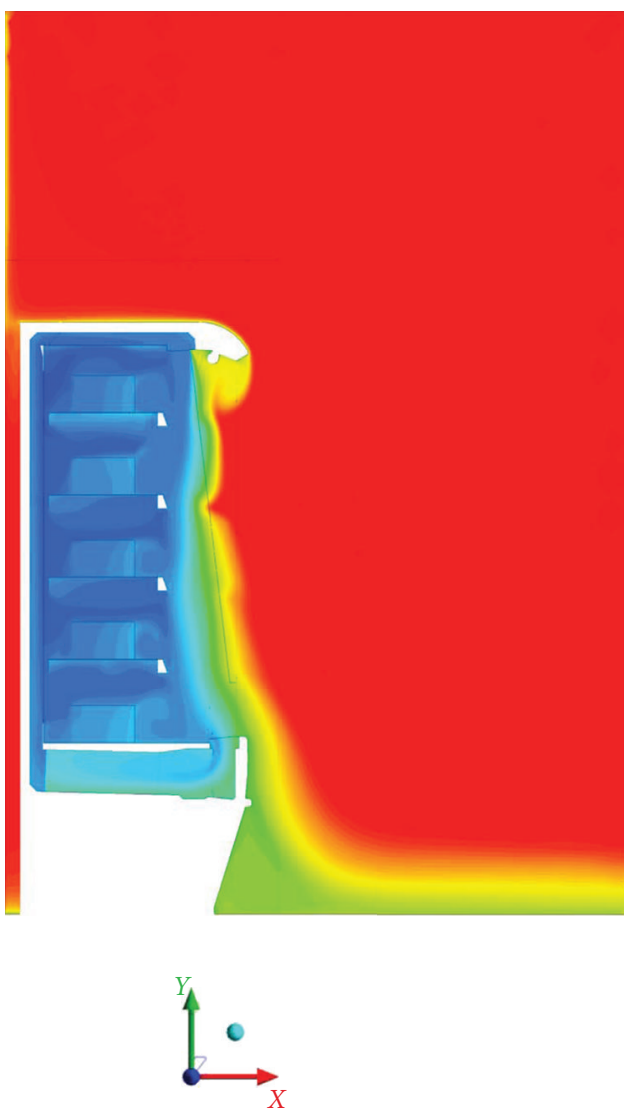

(a) computational domain
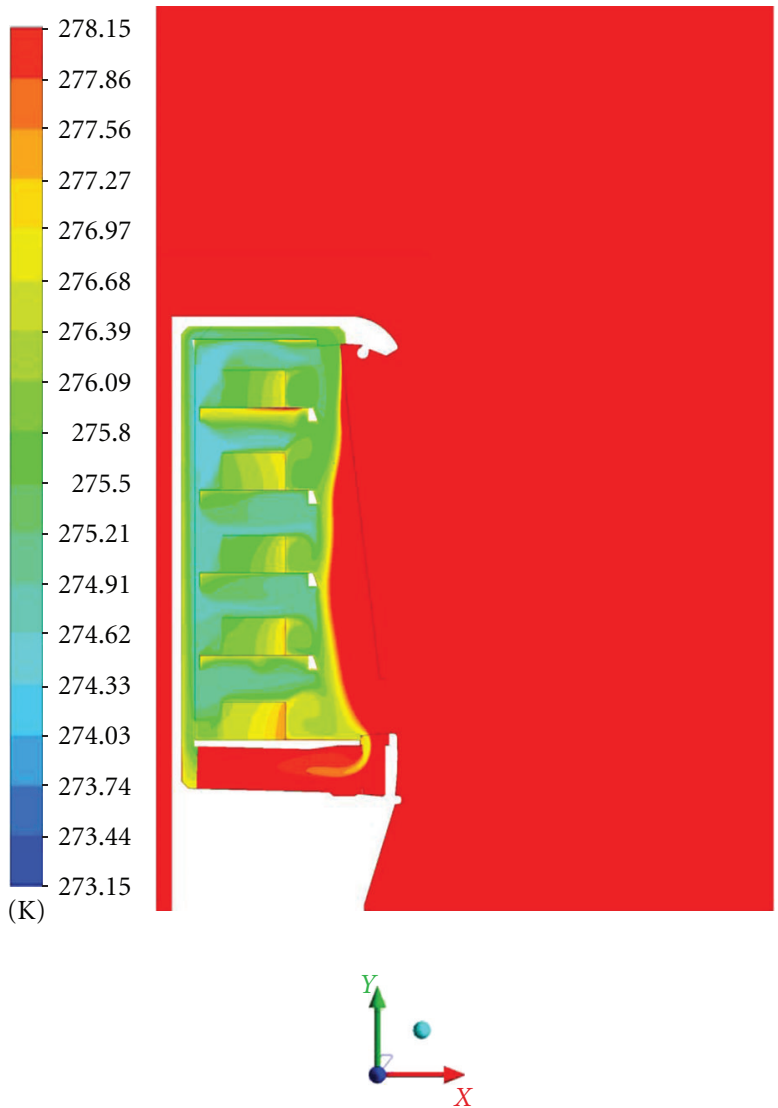

(b) products conservation zone (reduced scale)

FIgURE 9: Temperature field numerical predictions, $T(\mathrm{~K})$.

effect of a number of modifications that affect the equipment's overall performance, that is, aiming the reduction of thermal entrainment rate and maintaining stable air curtain momentum until it reaches RAG.

Based on the numerical predictions analysis, several parametric studies can be developed to evaluate the influence of some parameters in thermal entrainment and temperature distribution homogeneity inside products conservation region, as these factors are directly related with food safety and energy consumption. As determined by the numerical predictions analysis, these parameters involve fans velocity; hole diameters and their distribution on the backpanel perforation; DAG and RAG angles; guides and deflectors inside ducts, among others. In the future, parametric studies of the abovementioned parameters based on this detailed CFD model will be developed with the aim to analyse design modifications that improve the overall performance of the open display cabinet. 


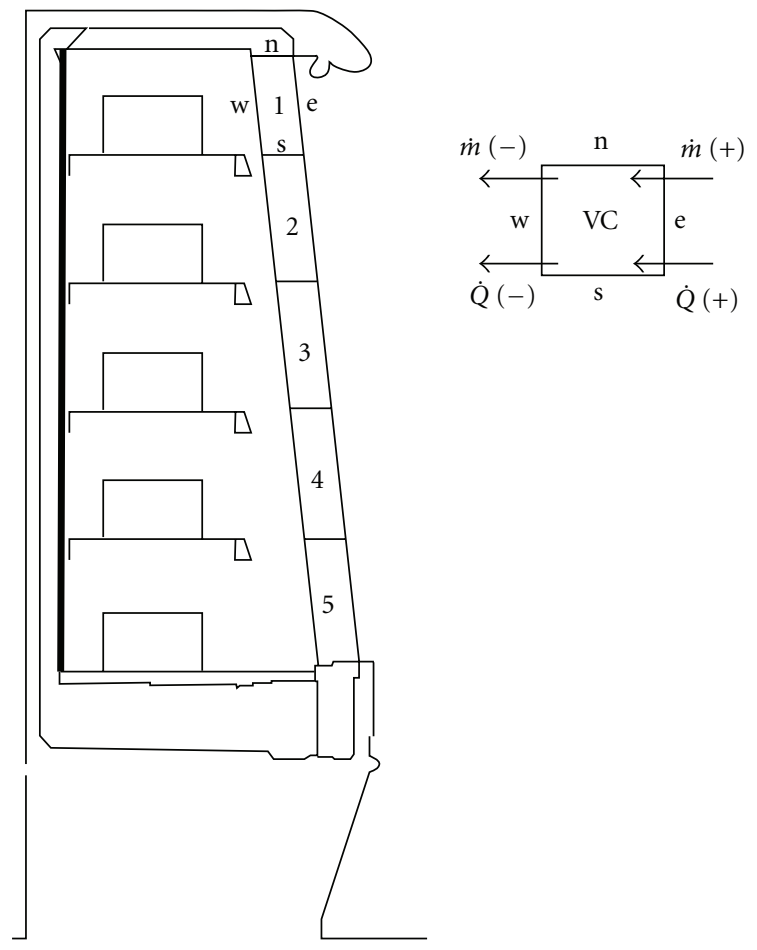

FIGURE 10: Subdivision of air curtain region by control volumes and sign convention of variables.

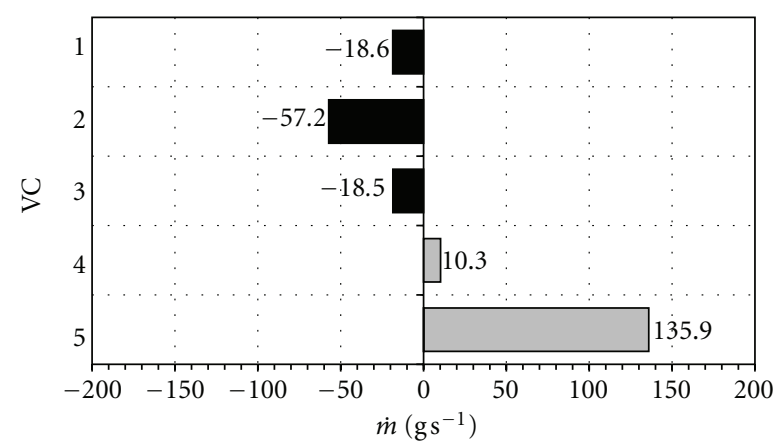

(a) West faces $(\mathrm{w})$

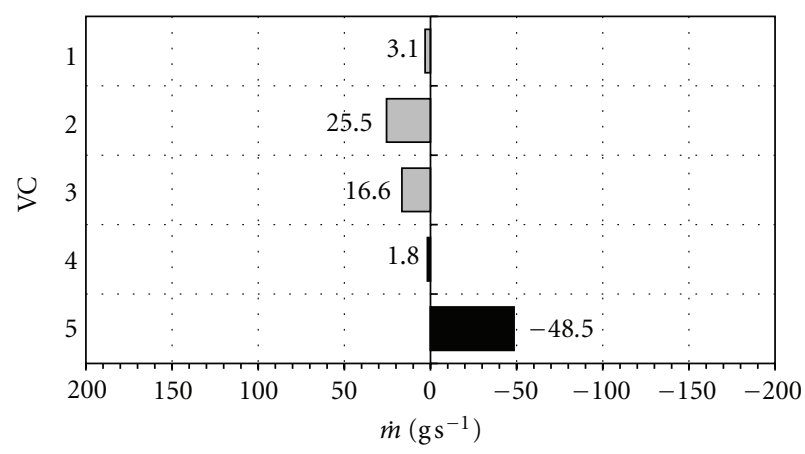

(b) East faces (e)

FIGURE 11: Mass flow rate predictions across East (exterior border) and West (interior border) of air curtain control volumes, per unit length.

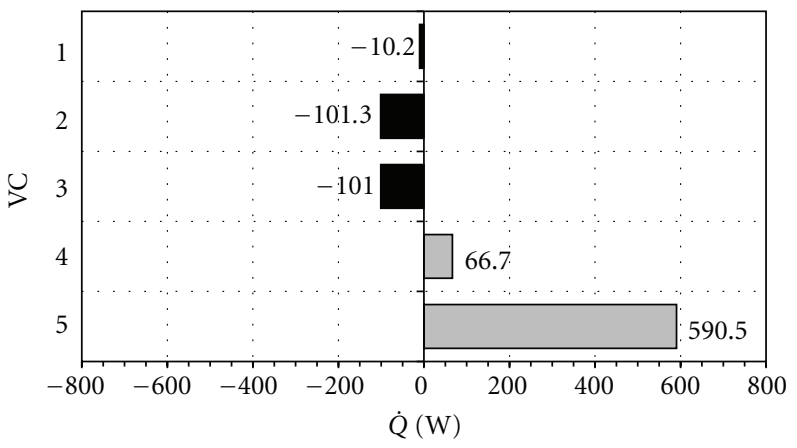

(a) West faces (w)

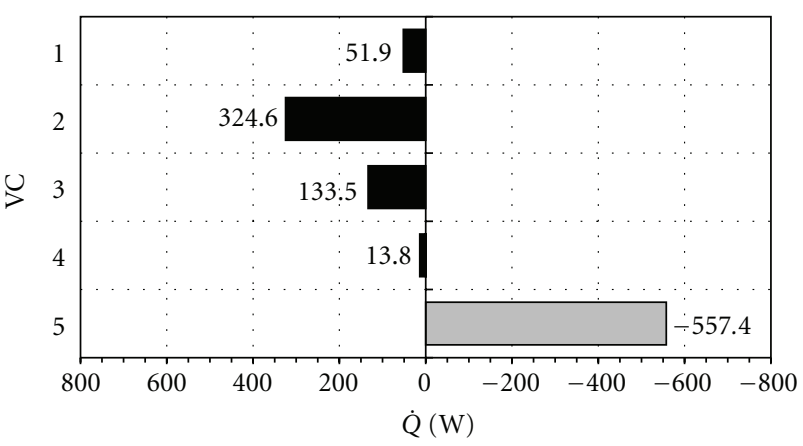

(b) East faces (e)

FIGURE 12: Heat transfer predictions across East (exterior border) and West (interior border) of air curtain control volumes, per unit length. 


\section{Nomenclature}

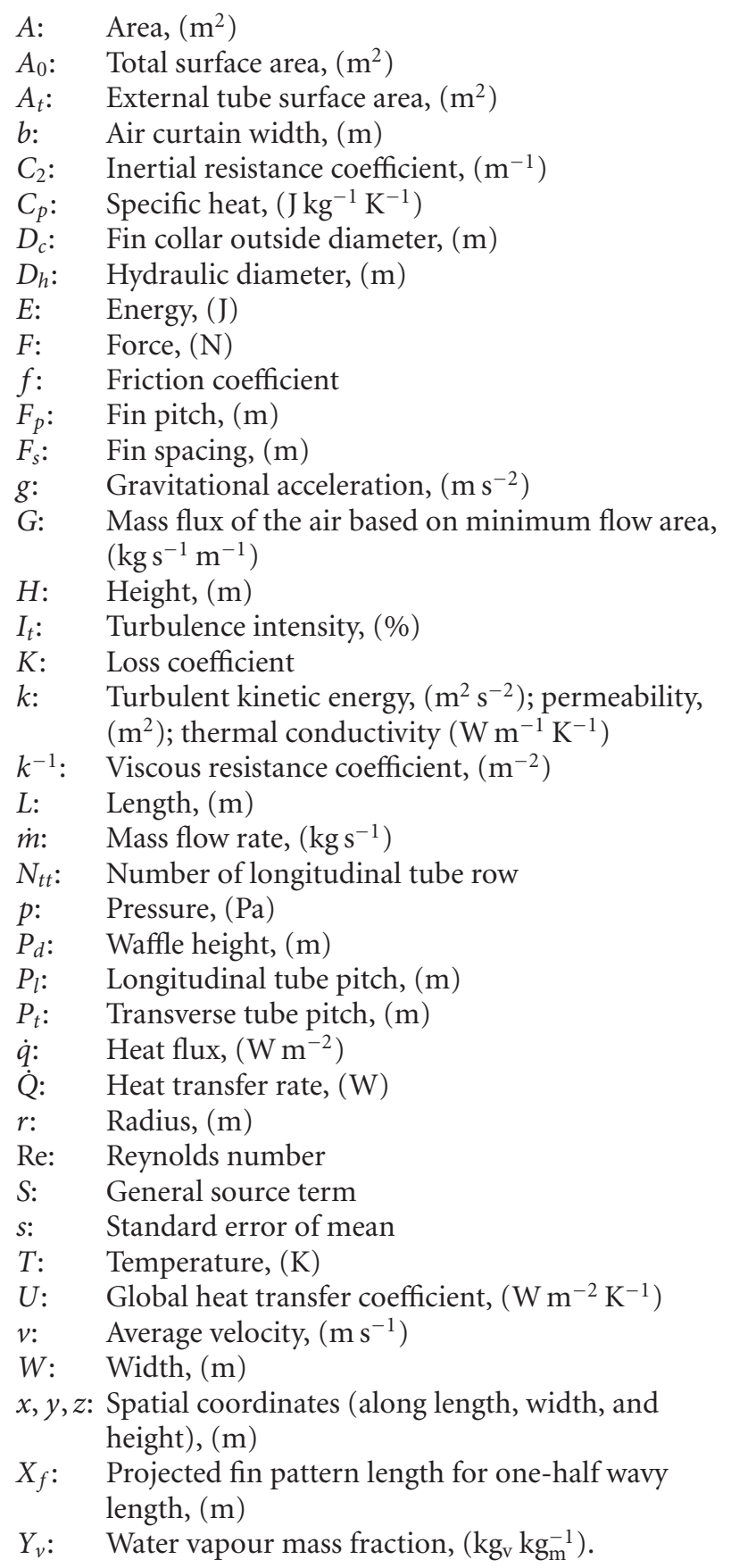

$\begin{array}{ll}e: & \text { Expansion } \\ \text { eq: } & \text { Equivalent } \\ \text { evap: } & \text { Evaporator } \\ \text { e, w, n, s: } & \text { Control volume faces identification (East, } \\ & \text { West, North, and South) } \\ f: & \text { Fin } \\ h: & \text { Hydraulic } \\ i: & \text { Component of cartesian directions } \\ & \text { according to } x, y, \text { and } z \\ \text { in: } & \text { Input; upstream } \\ \text { out: } & \text { Mixture } \\ \text { ref: } & \text { Output; downstream } \\ \text { refrig: } & \text { Reference } \\ \text { sup: } & \text { Surface } \\ t: & \text { Total; turbulent } \\ v: & \text { Water vapour; void. }\end{array}$

\section{Greek Symbols}

$\rho:$ Density, $\left(\mathrm{kg} \mathrm{m}^{-3}\right)$

$\varepsilon$ : Dissipation rate of turbulent kinetic energy, $\left(\mathrm{m}^{2} \mathrm{~s}^{-3}\right)$; emissivity; porosity

$\phi$ : Relative humidity, (\%); general dependent variable

$\mu$ : Dynamic viscosity, $\left(\mathrm{kg} \mathrm{m}^{-1} \mathrm{~s}^{-1}\right)$

$\sigma$ : Standard deviation; ratio of the minimum flow area to frontal area

$\sigma^{2}$ : Variance

$\omega$ : Absolute humidity, $\left(\mathrm{kg}_{\mathrm{v}} \mathrm{kg}_{\mathrm{a}}^{-1}\right)$

$\delta:$ Thickness, $(\mathrm{m})$

$\lambda$ : Convergence criterion.

\section{Acronyms}

ACML: Air curtain measuring location

BC: $\quad$ Boundary condition

CAD: Computer-aided design

CAE: Computer-aided engineering

CSML: Conservation space measuring location

DAG: Discharge air grille

ORDC: Open refrigerated display cabinet

PBP: Perforated backpanel

RAG: Return air grille

VC: Volume of Control

TEF: Thermal entrainment factor.

\section{Superscripts and Subscripts}

0: $\quad$ Total surface

a: Air

amb: Ambient

bb: Black body

c: Air curtain; contraction; cross-sectional; fin collar

comb: Honey comb

cons: Conservation

\section{Acknowledgments}

The authors wish to acknowledge the support of University of Beira Interior-Engineering Faculty-Electromechanical Engineering Department, Covilhã, Portugal (http://www.ubi.pt/) and of JORDÃO Cooling Systems, Guimarães, Portugal (http://www.jordao.com/). The authors do not have any conflict of interest is with the content of the manuscript. 


\section{References}

[1] R. Faramarzi, "Efficient display case refrigeration," ASHRAE Journal, vol. 41, no. 11, pp. 46-54, 1999.

[2] F. Billard and J. L. Dupont, "Industry as a partner for sustainable development e Refrigeration. In: International Institute of Refrigeration (IIR)," Final Report Prepared for UNEPUnited Nations Environment Programme, International Institute of Refrigeration (IIR), Paris, France, 2002.

[3] Freedonia, World Commercial Refrigeration EquipmentIndustry Study with Forecasts to 2014 \& 2019, The Freedonia Group Inc., Cleveland, Ohio, USA, 2011.

[4] D. Westphalen, R. Zogg, A. Varon, and M. Foran, "Energy savings potential for commercial refrigeration equipment," in Final Report Prepared for Building Equipment Division Office of Building Technologies, A. D. Little, Ed., U.S. Department of Energy (DOE), Cambridge, Mass, USA, 1996.

[5] P. D. Gaspar, L. C. C. Gonçalves, and R. A. Pitarma, "Experimental analysis of the thermal entrainment factor of air curtains in vertical open display cabinets for different ambient air conditions," Applied Thermal Engineering, 2010.

[6] P. D’Agaro, G. Cortella, and G. Croce, "Two- and threedimensional CFD applied to vertical display cabinets simulation," International Journal of Refrigeration, vol. 29, no. 2, pp. 178-190, 2006.

[7] I. Gray, P. Luscombe, L. McLean, C. S. P. Sarathy, P. Sheahen, and K. Srinivasan, "Improvement of air distribution in refrigerated vertical open front remote supermarket display cases," International Journal of Refrigeration, vol. 31, no. 5, pp. 902 910, 2008.

[8] ASHRAE, ASHRAE Handbook: Applications, American Society of Heating, Refrigerating and Air-Conditioning Engineers Inc., Washington, DC, USA, 2006.

[9] P. Bhattacharjee and E. Loth, "Simulations of laminar and transitional cold wall jets," International Journal of Heat and Fluid Flow, vol. 25, no. 1, pp. 32-43, 2004.

[10] Y.-G. Chen and X. L. Yuan, "Simulation of a cavity insulated by a vertical single band cold air curtain," Energy Conversion and Management, vol. 46, no. 11-12, pp. 1745-1756, 2005.

[11] B. S. Field and E. Loth, "Entrainment of refrigerated air curtains down a wall," Experimental Thermal and Fluid Science, vol. 30, no. 3, pp. 175-184, 2006.

[12] A. M. Foster, M. J. Swain, R. Barrett, P. D’Agaro, and S. J. James, "Effectiveness and optimum jet velocity for a plane jet air curtain used to restrict cold room infiltration," International Journal of Refrigeration, vol. 29, no. 5, pp. 692-699, 2006.

[13] L. P. C. Neto, M. C. G. Silva, and J. J. Costa, "On the use of infrared thermography in studies with air curtain devices," Energy and Buildings, vol. 38, no. 10, pp. 1194-1199, 2006.

[14] J. J. Costa, L. A. Oliveira, and M. C. G. Silva, "Energy savings by aerodynamic sealing with a downward-blowing plane air curtain-A numerical approach," Energy and Buildings, vol. 38, no. 10, pp. 1182-1193, 2006.

[15] G. Cortella, M. Manzan, and G. Comini, "CFD simulation of refrigerated display cabinets," International Journal of Refrigeration, vol. 24, no. 3, pp. 250-260, 2001.

[16] H. K. Navaz, R. Faramarzi, M. Gharib, D. Dabiri, and D. Modarress, "The application of advanced methods in analyzing the performance of the air curtain in a refrigerated display case," Journal of Fluids Engineering, Transactions of the ASME, vol. 124, no. 3, pp. 756-764, 2002.

[17] M. Axell and P. Fahlén, "Design criteria for energy efficient vertical air curtains in display cabinets," in Proceedings of the 21st IIR International Congress of Refrigeration, International
Institute of Refrigeration (IIR), Ed., International Institute of Refrigeration, Washington, DC, USA, 2003.

[18] H. K. Navaz, B. S. Henderson, R. Faramarzi, A. Pourmovahed, and F. Taugwalder, "Jet entrainment rate in air curtain of open refrigerated display cases," International Journal of Refrigeration, vol. 28, no. 2, pp. 267-275, 2005.

[19] A. M. Foster, M. Madge, and J. A. Evans, "The use of CFD to improve the performance of a chilled multi-deck retail display cabinet," International Journal of Refrigeration, vol. 28, no. 5, pp. 698-705, 2005.

[20] Y.-G. Chen, "Parametric evaluation of refrigerated air curtains for thermal insulation," International Journal of Thermal Sciences, vol. 48, no. 10, pp. 1988-1996, 2009.

[21] Y. T. Ge and S. A. Tassou, "Simulation of the performance of single jet air curtains for vertical refrigerated display cabinets," Applied Thermal Engineering, vol. 21, no. 2, pp. 201-219, 2001.

[22] Y. T. Ge, S. A. Tassou, and A. Hadawey, "Simulation of multi-deck medium temperature display cabinets with the integration of CFD and cooling coil models," Applied Energy, vol. 87, no. 10, pp. 3178-3188, 2010.

[23] Y.-G. Chen and X. L. Yuan, "Experimental study of the performance of single-band air curtains for a multi-deck refrigerated display cabinet," Journal of Food Engineering, vol. 69, no. 3, pp. 261-267, 2005.

[24] K.-Z. Yu, G. L. Ding, and T. J. Chen, "A correlation model of thermal entrainment factor for air curtain in a vertical open display cabinet," Applied Thermal Engineering, vol. 29, no. 1415, pp. 2904-2913, 2009.

[25] P. D. Gaspar, L. C. C. Gonçalves, and R. A. Pitarma, "Experimental analysis of the thermal entrainment three dimensional effects in recirculated air curtains," in Proceedings of the 10th International Conference on Air Distribution in Rooms (ROOMVENT '07), Helsinki, Finland, 2007.

[26] J. A. Evans, S. Scarcelli, and M. V. L. Swain, "Temperature and energy performance of refrigerated retail display and commercial catering cabinets under test conditions," International Journal of Refrigeration, vol. 30, no. 3, pp. 398-408, 2007.

[27] EN-ISO Standard, "Refrigerated display cabinets, parts 1 and 2," Tech. Rep. 23953, ISO-International Organization for Standardization, Geneva, Switzerland, 2005.

[28] J. H. Ferziger and M. Perić, Computational Methods for Fluid Dynamics, Springer-Verlag, Berlin, Germany, 3rd edition, 2002.

[29] V. Yakhot and S. A. Orszag, "Renormalization group analysis of turbulence. I. Basic theory," Journal of Scientific Computing, vol. 1, no. 1, pp. 3-51, 1986.

[30] P. D. Gaspar and R. A. Pitarma, "Desempenho de modelos de turbulência em regime convectivo misto-Aplicação a caso de estudo," in Proceedings of Engenharia'03-Inovação e Desenvolvimento, Universidade da Beira Interior, Covilhã, Portugal, 2003.

[31] P. D. Gaspar and R. A. Pitarma, "Simulação de equipamento industrial de refrigeração: estudo de caso," in Proceedings of the 6th Congresso de Métodos Numéricos en Ingenieria/7th Congresso de Nacional de Mecânica Aplicada e Computacional, Laboratório Nacional de Engenharia Civil, Lisboa, Portugal, 2004.

[32] P. D. Gaspar and R. A. Pitarma, "CFD Codes efficiency case study: ability to perform numerical simulations in the refrigerated compartment of a foodstuff transportation vehicle," in Proceedings of the 9th International Conference on Air Distribution in Rooms (ROOMVENT '04), Coimbra, Portugal, 2004. 
[33] P. D. Gaspar and R. A. Pitarma, "Evaluation of CFD codes by comparison of numerical predictions of an air-conditioned room case study," in Advanced Computational Methods in Heat Transfer VIII, B. Sundén, C. A. Brebbia, and A. Mendes, Eds., Computational Studies (5), WIT Press, Southampton, UK, 2004.

[34] W. Rodi, Turbulence Models and Their Application in Hydraulics. A State of the Art Review, International Association for Hydraulics Research, Madrid, Spain, 1980.

[35] B. E. Launder and D. B. Spalding, "The numerical computation of turbulent flows," Computer Methods in Applied Mechanics and Engineering, vol. 3, no. 2, pp. 269-289, 1974.

[36] R. I. Issa, "Solution of the implicitly discretised fluid flow equations by operator-splitting," Journal of Computational Physics, vol. 62, no. 1, pp. 40-65, 1986.

[37] S. V. Patankar, Numerical Heat Transfer and Fluid Flow, Hemisphere Publishing Corporation, Washington, DC, USA, 1980.

[38] D. S. Jang, R. Jetli, and S. Acharya, "Comparison of the PISO, SIMPLER, and SIMPLEC algorithms for the treatment of the pressure-velocity coupling in steady flow problems," Numerical heat transfer, vol. 10, no. 3, pp. 209-228, 1986.

[39] B. van Leer, "Towards the ultimate conservative difference scheme. V. A second-order sequel to Godunov's method," Journal of Computational Physics, vol. 32, no. 1, pp. 101-136, 1979.

[40] M. F. Modest, Radiative Heat Transfer, McGraw-Hill, New York, NY, USA, 1993.

[41] B. N. George and D. R. Buttsworth, "Investigation of an open refrigeration cabinet using computational simulations with supporting experiments," in Proceedings of the 2000 ASME International Mechanical Engineering Congress and Exposition, Orlando, Fla, USA, 2000.

[42] P. D. Gaspar, L. C. C. Gonçalves, and R. A. Pitarma, "Influência da localização da condição de fronteira de pressão fixa e constante na simulação de aberturas ao ar ambiente," in Proceedings of the Congresso de Métodos Numéricos em Engenharia-(CMNE' 07)/Congresso Ibero Latino-Americano sobre Métodos Computacionais em Engenharia-(CILAMCE '07), Porto, Portugal, 2007.

[43] EN-ISO Standard, "Household refrigerating appliancesfrozen food storage cabinets and food freezers-characteristics and test methods," Tech. Rep. 15502, ISO-International Organization for Standardization, Geneva, Switzerland, 2005.

[44] ASHRAE, ASHRAE Handbook: Fundamentals, American Society of Heating, Refrigerating and Air-Conditioning Engineers Inc., Washington, DC, USA, 1997.

[45] J. Bear, Dynamics of Fluids in Porous Media, Dover Publications Inc., Mineola, NY, USA, 1988.

[46] R. H. Perry and D. W. Green, Perry's Chemical Engineers' Handbook, McGraw-Hill, New York, NY, USA, 1997.

[47] L. Tang, K. A. Moores, C. Ramaswamy, and Y. Joshi, "Characterizing the thermal performance of a flow through electronics module (SEM-E format) using a porous media model," in Proceedings of the IEEE 14th Annual Semiconductor Thermal Measurement and Management Symposium, pp. 68-77, March 1998.

[48] T. S. Kwon, C. R. Choi, C. H. Song, and W. P. Baek, "A threedimensional CFD calculation of boron mixing behaviors at the core inlet," in Proceedings of the 10th International Topical Meeting on Nuclear Reactor Thermal Hydraulics (NURETH10), Seoul, Korea, 2003.

[49] W. Tong, "Numerical analysis of flow field in generator endwinding region," International Journal of Rotating Machinery, vol. 2008, Article ID 692748, 2008.
[50] I. E. Idel'Cik, Memento des Pertes de Charge-Coefficients dês Pertes de Charge Singulières et de Pertes de Charge par Frottement, Direction dês Etudes et Recherces D'electricite de France, Eyrolles, Paris, France, 1969.

[51] C. C. Wang, Y. T. Lin, C. J. Lee, and Y. J. Chang, "Investigation of wavy fin-and-tube heat exchangers: a contribution to databank," Experimental Heat Transfer, vol. 12, no. 1, pp. 7389, 1999.

[52] W. M. Kays and A. L. London, Compact Heat Exchangers, McGraw-Hill, New York, NY, USA, 3rd edition, 1984.

[53] F. C. McQuiston and J. D. Parker, Heating, Ventilating, and Air Conditioning-Analysis and Design, John Wiley \& Sons, New York, NY, USA, 4th edition, 1994.

[54] R. Chandrasekharan, P. Verma, and C. W. Bullard, "Development of a design tool for display case evaporators," International Journal of Refrigeration, vol. 29, no. 5, pp. 823-832, 2006.

[55] C. O. Gill, T. Jones, A. Houde et al., "The temperatures and ages of packs of beef displayed in multi-shelf retail cabinets," Food Control, vol. 14, no. 3, pp. 145-151, 2002.

[56] Y. L. Lu, W. H. Zhang, P. Yuan, M. D. Xue, Z. G. Qu, and W. Q. Tao, "Experimental study of heat transfer intensification by using a novel combined shelf in food refrigerated display cabinets (Experimental study of a novel cabinets)," Applied Thermal Engineering, vol. 30, no. 2-3, pp. 85-91, 2010.

[57] E. Hammond, J. Quarini, and A. Foster, "Development of a stability model for a vertical single band recirculated air curtain sealing a refrigerated cavity," International Journal of Refrigeration, vol. 34, no. 6, pp. 1455-1461, 2011.

[58] G. Cortella, "CFD-aided retail cabinets design," Computers and Electronics in Agriculture, vol. 34, no. 1-3, pp. 43-66, 2002. 

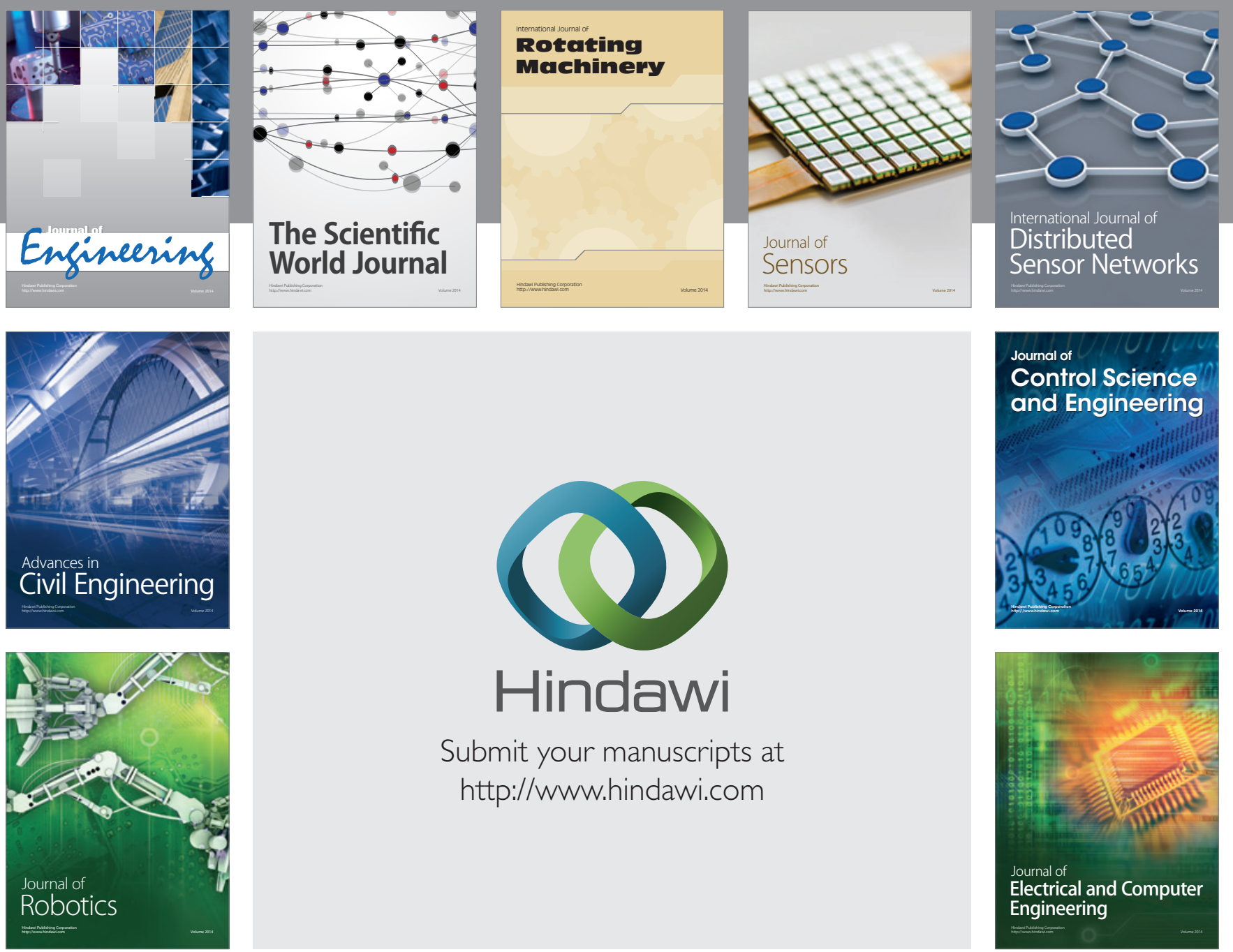

Submit your manuscripts at

http://www.hindawi.com
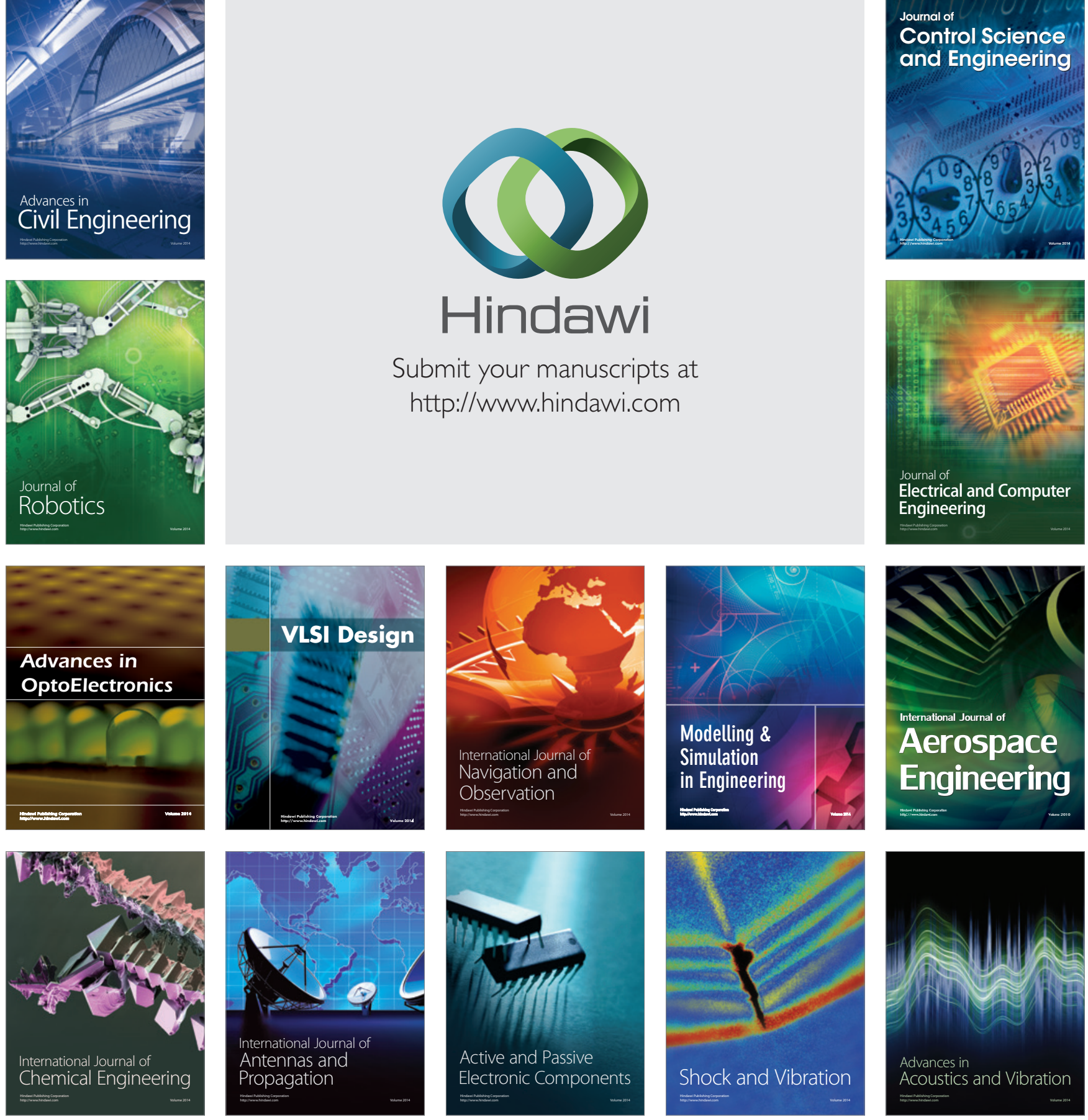